\title{
Going carless in different urban fabrics: socio-demographics of household car ownership
}

\author{
L. E. Karjalainen ${ }^{1,2}$ (D) M. Tiitu ${ }^{1}$ (D) J. Lyytimäki ${ }^{1}$ (D) $\cdot$ V. Helminen ${ }^{1}$ (D) P. Tapio ${ }^{3}$ (D) \\ A. Tuominen ${ }^{4}$ (D) T. Vasankari $^{5}$ (D) . J. Lehtimäki ${ }^{1}$ (D) $\cdot$ R. Paloniemi ${ }^{1}$ (i)
}

Accepted: 16 October 2021 / Published online: 21 November 2021

(c) The Author(s) 2021

\begin{abstract}
Diverse physical features of urban areas alongside socio-demographic characteristics affect car ownership, and hence the daily mobility choices. As a case of sustainable mobility, we explore how various urban environments and socio-demographics associate with the spatial and social distribution of household car ownership and carlessness in the Helsinki Metropolitan Area, Finland. Three urban fabrics characterizing the study area are established based on the transportation mode (walking, public transportation, or automobile) the physical urban environment primarily supports. The national level Monitoring System of Spatial Structure and Urban Form database, and the National Travel Survey (2016) are utilized to further include spatial and socio-demographic variables into our analysis across these fabrics. Our results show that households with and without cars differ in terms of residential distance to the city center, neighborhood density, house type, and socio-demographic profiles. Single pensioners and students are most likely to be carless, whereas families represent the opposite. Within the carless households the differences are also evident between different groups. For the more affluent households residing in dense and well-connected areas, and mostly possessing driver's licenses, carlessness is presumably a choice. Contrarily, many other carless households represent the less affluent often located in the more distant, low-density, and less accessible areas, while also possessing less driver's licenses, making carlessness more of a constraint, as the local urban fabric does not support such lifestyle. Consequently, carless households should be increasingly recognized as a focus group in sustainable urban planning in terms of identifiable best practices and potential vulnerability.
\end{abstract}

Keywords Carless households · Car ownership · Transportation equity $\cdot$ Sustainable mobility $\cdot$ Urban fabrics

\footnotetext{
L. E. Karjalainen

linda.karjalainen@syke.fi

Finnish Environment Institute, Helsinki, Finland

2 University of Helsinki, Helsinki, Finland

3 University of Turku, Turku, Finland

4 VTT Technical Research Centre of Finland Ltd, Espoo, Finland

5 UKK Institute, Tampere, Finland
} 


\section{Introduction}

Sustainable mobility and adequate physical activity are intertwined phenomena in urban areas. Urban design can support or forestall walking, cycling, and public transportation, and private car use, while individual socio-demographic traits also influence travel behavior. Reduced driving, increased active transportation, and car-free urban areas have been set as policy goals in many cities globally (Nieuwenhuijsen and Khreis 2016; Scheepers et al. 2014). The desired direction aims at decreased environmental effects caused by motorized transportation, as well as increased physical activity of citizens alongside the related health benefits. Furthermore, the space reserved for, and consumed by, motorized transportation can be reallocated towards active transportation pathways, public transportation infrastructure, public spaces, and green areas (Nieuwenhuijsen and Khreis 2016).

While increased car use may be showing signs of leveling off in some countries (Focas and Christidis 2017), it has nonetheless established itself as a defining feature of cities. Even with the presence of new alternative transportation services and modes, the use of private cars is still linked to various personal motivations and strong emotions (von Behren et al. 2020; Steg 2005). Urban space has been favorably allocated towards car travel for much of the twentieth century worldwide, thus pushing aside, in particular, the physically active modes in a competition over the limited road space (Gössling et al. 2016). Further, car travel has been supported by the promise of economic growth through oil and car manufacturing markets (Sheller and Urry 2000), and the prolonged and failed attempts to externalize the societal costs it causes (Nieuwenhuijsen and Khreis 2016). Simultaneously, physical activity amongst urban dwellers has significantly decreased (Nieuwenhuijsen and Khreis 2016). The spreading of physical inactivity has been labeled as a global pandemic causing up to five million deaths annually (Sallis et al. 2016; Badland and Schofield 2005). Sedentary behavior is increasing in the daily life through passive transportation, passive professions, and leisure time that does not engage us physically. On average, only $7 \%$ of European adults exercise regularly, and mere $23 \%$ of boys and $14 \%$ of girls meet the recommendations for adequate physical activity on a daily basis (World Health Organization 2018). Walking as a main mode for trips in the European Union (EU) member state cities fluctuates between approximately 15 and 50\%, whereas cycling varies between zero and $70 \%$ (Steenberghen et al. 2017). In addition to physical inactivity, excessive car travel brings about air pollution that further contributes to negative health impacts such as respiratory and cardiovascular diseases (Nieuwenhuijsen 2016; Nieuwenhuijsen and Khreis 2016).

Dense, compact, connected, diverse, safe, and both physically and socio-economically accessible urban areas and transportation networks provide the basis for a shift towards sustainable and active mobility, and the increased use of sustainable modes of transportation as alternatives to the private car (Sallis et al. 2016; Nieuwenhuijsen and Khreis 2016). A carless lifestyle can be used as an indicator of accessible and well-connected areas where an active, equitable and sustainable alternative to the use of private car is provided for daily travel (Nieuwenhuijsen and Khreis 2016; Brown 2017; Banister 2018). Newman et al. (2016) have advanced this linkage between the features of the physical urban environment and different mobility lifestyles by defining three urban environment types, urban fabrics, that support either a carless lifestyle (walking urban fabric, and transit fabric) or a cardependent lifestyle (automobile fabric). In other words, some urban environments enable and induce carlessness, while others support or even require car use. 
When studying car ownership, and carlessness in particular, the dichotomy of carlessness cannot be overlooked. It refers to voluntary and involuntary carlessness, or car-free and carless citizens as coined by Brown (2017), where individuals or households either choose to go carless, or cannot, for example, afford a car in which case carlessness is not a choice (Brown 2017; Mitra and Saphores 2017). While car ownership and its links to the urban environment have been widely studied in academic literature-and the urban environment and socio-demographic characteristics of carlessness to some extent-combinations of spatial and socio-demographic variables as determinants for car ownership and carlessness in urban areas remain under researched (Banister 2018; Mitra and Saphores 2017). Moreover, prior carlessness research has largely focused on North America, while the few European studies (Chevallier et al. 2018; Motte-Baumvol et al. 2010; Sattlegger and Rau 2016; Lagrell et al. 2018) have been mainly qualitative in nature or focused on influential factors for national scale car ownership (Oakil et al. 2014).

In this paper, we present the first combined analysis of influential spatial and sociodemographic variables for urban car ownership and carlessness. We ask how car ownership and carlessness are spatially distributed in the Helsinki Metropolitan Area (HMA), Finland, and how they associate with the features of the physical urban environment and the socio-demographics of the households. We apply a spatial analysis on a 250-m grid that integrates urban features, car ownership, and relevant socio-demographic characteristics. Our focus is on the carless, one-car, and multiple-car households in the different urban fabrics-the typology used to classify the urban environment into areas that primarily support walking, public transportation, or car use (Newman et al. 2016). Here, the concept of 'physical urban environment' is applied to address the physical structures and features of the urban form, and 'car ownership' to include households with and without cars unless specified. Carlessness as a choice or a constraint is identified and explored through criteria that combines the residential locations in the different urban fabrics and the lifestyles they enable or restrict, with the key socio-demographic household characteristics for chosen or constrained carlessness, as identified in previous literature. The purpose of this paper is thus three-fold: (1) to construct a spatial representation of varying household car ownership classes $(0,1$, and multiple), (2) to identify influential physical urban features for these household car ownership classes, and (3) to explore socio-demographic variables related to these household car ownership classes within each urban fabric to reflect potential choices and constraints. This integrated analysis thus equips us with explanatory features of car ownership and carlessness that enables the detection of potentials for lessened car use as well as vulnerabilities.

\section{Urban car ownership and carlessness}

The physical urban environment creates the frame for mobility. Distances, densities, diversity, design, and accessibility of routes for different transportation modes define the options for travelers (e.g. Mitra and Saphores 2017; Van Acker and Witlox 2010). However, these physical urban environment features do not alone dictate mobility choices, as socio-demographic characteristics, such as age, number of children, gender, and income, also influence these decisions (Mitra and Saphores 2017). As the following brief review points out, these two extensive sets of characteristics have however not been combined in carlessness research in the urban context. Behavioral aspects, such as personal values, preferences, 
worldviews, intentions, and motivations comprise the third element in mobility choices, but due to unavailable data they are not included in our analysis.

\section{Role of the physical urban environment in car ownership and carlessness}

In car ownership and carlessness studies, the key features of the urban environment supporting car-free lifestyles consist of densities for population, jobs, street blocks, and transportation networks (e.g. Mitra and Saphores 2017; Kühne et al. 2018; Clark et al. 2016; Bhat and Guo 2007). Distances to workplaces, business zones, and commute times by different modes (e.g. Delbosc and Currie 2012; Noblet et al. 2014; Scheiner 2010; Bhat and Guo 2007) are also commonly applied. Accessibility is utilized in a myriad of ways, for example, as temporal modal accessibility or as the availability of local key services and public transportation stops (e.g. Kühne et al. 2018; Mitra and Saphores 2017; Delbosc and Currie 2012; Scheiner 2010; Clark et al. 2016; Bhat and Guo 2007). Neighborhood and housing types (e.g. Blumenberg et al. 2018; Needles Fletcher et al. 2005; Kühne et al. 2018), residential locations (e.g. Delbosc and Currie 2012; Clark et al. 2016), and mixed land-use (e.g. Mitra and Saphores 2017) are furthermore deemed influential. To put it bluntly, car travel decreases when distances to services, centers, or sub-centers decrease, and urban density, compactness, and service diversity increase.

The Urban fabrics approach divides the city into walking, transit, and automobile fabrics, based on the primary transportation mode the local urban structure supports (Newman et al. 2016). Fabric thus refers to the physical attributes of the urban environment, that are applied to classify the urban area into three different transportation environments. The areas of urban fabrics are not defined by the actual use of different travel modes but by the qualities of the physical urban environment that enable certain mobility choices. Walking urban fabric is compact, connected, and dense, with short blocks, narrow streets, high share of walking, public spaces, and diverse local services. The Transit urban fabric is more arterial in its coverage, as it spans across the city according to the bus and rail-based routes. The densities are medium and the environment accommodative specifically for public transportation users, but also somewhat to pedestrians and car users. The Automobile urban fabric is represented by low densities, long distances, wide roads, abundant parking facilities, high car use, large but dispersed shopping facilities, and a low number of functions accessible without a car in general (Newman et al. 2016). This division of urban areas into three different fabrics is a generalization of a more fine-grained range of physical environments with different densities and urban features. Newman et al. 2016 also recognize different subtypes of the fabrics based on distance from the city center (e.g. inner walking fabric, outer walking fabric, inner transit fabric, and outer transit fabric). Each urban fabric has its characteristic qualities, but the fabrics can partially overlap. These qualities reflect the functions and lifestyles of different areas and enable certain types of mobility choices while restricting others.

However, living in a specific urban fabric does not automatically mean adhering to the mobility choices that the fabric primarily enables (Ettema and Nieuwenhuis 2017). For example, dense areas with mixed land-use do not only accommodate carless households, and respectively, outer suburbs also harbor households that rely on poor transit connections instead of owning a car, often due to economic constraints (Bhat and Guo 2007). This phenomenon is also referred to as residential self-selection, meaning 
that people opt for residential locations matching their desired travel behavior, but that personal attitudes and preferences towards travel modes also play a role (Ettema and Nieuwenhuis 2017). The urban fabric typologies create the basis for our analysis of the HMA and a classification for the voluntary, involuntary (and vulnerable) groups of the carless population, as the fabrics dictate what type of mobility lifestyles are supported or challenging in the different urban environments. Essential to our analysis of carlessness as a choice or a constraint is that a carless lifestyle in the automobile urban fabric is categorized as difficult (Newman et al. 2016).

\section{Role of socio-demographics in car-ownership and the voluntary or involuntary carlessness}

Owning a car is a decision with long-term influence on travel mode choice and daily routines (e.g. Bhat and Guo 2007; Van Acker and Witlox 2010; Oakil et al. 2014). Yet, it is also argued that many households are carless for only short periods of time (Klein and Smart 2017). Life events, such as gaining employment and growth in family size have been attached to increases in car ownership, while loss of employment (including retirement) and a decrease in family size (e.g. divorce or children leaving home) tend to have the opposite effect (Blumenberg et al. 2018; Clark et al. 2016; Oakil et al. 2014). Moreover, a UK study (Clark et al. 2016) of car ownership development over one's life-course shows young adults and the elderly, particularly those in retirement, owning less cars than co-habiting couples or families. This 'standard' model of the affluent global north can however be challenged with the current diversity of households and life-courses as well as various lifestyles of different generations. Additionally, at times household car ownership does not guarantee car availability if several household members are dependent on the same car (Blumenberg et al. 2018). On the other hand, carless individuals, particularly the elderly, can have access to car-use as passengers through friends and relatives with cars (Mattioli 2014).

A review by Mitra and Saphores (2017) suggests that the socio-demographic characteristics of carless households tend to consist of lower income levels, lower education levels, and smaller family sizes, as compared to households owning at least one car, while car ownership has been shown to increase with growing income and family size (Kühne et al. 2018). Voluntary and involuntary carlessness divisions in literature are largely based on socio-demographic characteristics and personal motivations. Beyond the carlessness literature, individuals are similarly divided into choice and captive users of different transportation modes-either choosing to use, for example, public transportation or the private car, or having no other options and thus being reliant to a car or public transportation (Jacques et al. 2013; Beimborn et al. 2003).

In the North American context, carless households have generally been identified to be carless particularly due to economic constraints as opposed to a conscious choice to go 'car-free' (Blumenberg et al. 2018; Brown 2017; Klein and Smart 2017; Mattioli 2014). However, those households that have reported themselves as voluntarily carless state environmental concerns and a non-existent need for a car as the main reasons to go carless, while the involuntarily carless households list the aforementioned economic constrains, and additionally health and age-related issues alongside the inability to drive as reasons for not owning a car (Brown 2017). Similarly, Lagrell et al. (2018) in their study of carless families in Gothenburg, Sweden, found that a decision to go carless was motivated by environmental or other moral concerns. Importantly, the voluntarily carless households, with their usually higher incomes than their involuntarily carless counterparts, are financially 
able to choose a well-connected, mixed, and dense neighborhood to live in (Kühne et al. 2018; Mitra and Saphores 2017; Lagrell et al. 2018; Blumenberg et al. 2018; Chevallier et al. 2018).

Research into the dichotomy of carlessness and the chosen car-free lifestyle, is a 'roadless-travelled'. Currently, much of the research on different types of carlessness still focuses on the culturally highly car-dependent North America, and a sole focus on urban environments is rare. Investigations over a wider selection of influential socio-demographic aspects, built environment features, lifestyles and attitudes, and other car ownership related determinants for carlessness in urban areas continue to be sought after (Kühne et al. 2018).

\section{Material and methods}

\section{Case study on the Helsinki Metropolitan Area urban core area}

The Helsinki Metropolitan Area (HMA) is located on the southern coast of Finland, Europe, on the $60^{\circ} \mathrm{N}$ latitude, making Helsinki the second northernmost capital city of the world. It has 1.17 million inhabitants (in 2019) and contains four municipalities. The public transportation system consists of an extensive bus network, an inner-city tram system, metro lines connecting western and eastern subcenters to the city center of Helsinki, and a commuter train network linking additional subcenters, peri-urban centers, and the airport to the city center of Helsinki. On average, $27 \%$ of the trips in HMA are made by walking, $6 \%$ by cycling, $21 \%$ by public transportation, $44 \%$ by car, and $2 \%$ by other travel modes (Traficom 2018). The city of Helsinki has ambitious targets to double the amount of cycling by the year 2030, supported by the increasingly extensive bicycle lane network. The capital Helsinki has been described as a successful vanguard of sustainable mobility and active transportation due to systematic long-term advocacy of active travel modes (Saidla 2018).

An overwhelming share of the HMA population (1.07 million) resides within the southern part of the HMA, referred to as the urban core area. Our case study focuses on this area. The core area is defined according to the Geographical Information Systems (GIS) based Travel-related Urban Zones dataset (Finnish Environment Institute 2015), and it includes areas up to $10-15 \mathrm{~km}$ ground distance from the center of Helsinki, or an extended distance of 20-25 km from the city center along the main railway lines.

\section{Material}

Two national datasets were applied. (1) The Monitoring System of Spatial Structure and Urban Form (YKR) (Finnish Environment Institute 2020) was used for analyzing the spatial distribution of household car ownership. The data are a statistical grid with a spatial resolution of $250 \mathrm{~m}$. This dataset consists of a collection of physical urban environment variables, including the total number of households accompanied with the information of the distribution of car ownership (0, 1, or multiple) within one grid cell. (2) The National Travel Survey (NTS), provided by Finnish Transport and Communications Agency Traficom (Traficom 2018), was utilized. The data are a sample-based survey collected in 2016 with $\mathrm{x}$ and $\mathrm{y}$ coordinates for home and destinations for each respondent. The location of the respondents was geocoded based on their home address. Because of our focus on car ownership, we only included survey respondents who were 18 years or older, as this was 
the age limit for obtaining a driver's license in Finland in 2016. This left us with 2,921 respondents for the analysis. Each respondent was then classified in terms of the urban fabrics based on the location of their home and treated as a representative of households throughout the analyses. Additionally, we calculated variables to describe the accessibility and neighborhood qualities for each NTS respondent based on their home location using several GIS datasets: the YKR (Finnish Environment Institute 2016b); Building and Dwelling Register BDR (Finnish Environment Institute 2016a); Helsinki Region Travel Time Matrix dataset (Tenkanen et al. 2018); Travel-related urban zones (Finnish Environment Institute 2017); A.C. Nielsen grocery store register (A.C. Nielsen Ltd and Finnish Environment Institute 2014); Statistics Finland (2018); Corine Land Cover (Finnish Environment Institute 2018); and socio-demographic variables from the NTS (Traficom 2018). The use of individual datasets is explained in Sect. (Variables for car ownership and carlessness) and Appendix.

\section{HMA urban core area classification and data subsets}

The spatial distribution of different urban fabrics was identified in the case area using the methodology introduced by Helminen et al. (2020). The classification is based on an overlay analysis of combined density of residents and jobs per hectare, prevalence of a grocery store, and public transportation supply. The following thresholds (identified according to available literature and in cooperation with local planners) were applied: Walking and transit fabrics have (1) a combined density of residents and jobs of at least 20/ha, (2) maximum distance to a grocery store of $500 \mathrm{~m}$, and (3) a maximum distance of $250 \mathrm{~m}$ to a public transportation stop with a headway of $15 \mathrm{~min}$ for bus or $700 \mathrm{~m}$ for railway stations. The difference between the walking and transit fabrics is their distance to the city center: the urban fabrics are further identified according to different distance thresholds. The Euclidean distance of $2 \mathrm{~km}$ from the city center signifies the border of the walking fabrics and the inner transit and automobile fabrics. The remaining areas were classified as automobile fabric. Then, the classifications were finalized by dimensional circles (1, 2, and $8 \mathrm{~km})$ from the city center (Fig. 1). At this point the walking, transit, and automobile fabrics were treated as inner and outer categories based on their distance from the city center point, and the spatial representation includes inner and outer sub-centers, as well. $8 \mathrm{~km}$ marks the border between the inner transit and automobile fabrics and the outer transit and automobile fabrics. Additionally, inner and outer sub-centers were identified according to the Travelrelated Urban Zones database (Finnish Environment Institute 2015).

The classification of urban fabrics presented in Fig. 1 was generalized (from 8 spatial classes to 3 classes) for improved legibility of the results and to ensure a statistically adequate number of NTS respondents with varying car ownership in each spatial class, i.e. urban fabric. The data were thus organized into three subsets by combining similar spatial classes with similar car ownership rates in a way that we could form three subsets with adequate and as equal number of respondents as possible. First, Walking urban fabric covering the inner and outer walking fabrics, the inner transit fabric, and the inner sub-centers consisted of 895 observations. Second, Transit urban fabric consisting of the outer subcenters and the outer transit fabric had 1181 observations. Third, Automobile urban fabric composed of the inner and outer automobile fabrics had 845 observations in total. NTS data were weighted to avoid biases related to age and sex distributions between the survey respondents and the actual distribution in the study area. The weighting was carried out 


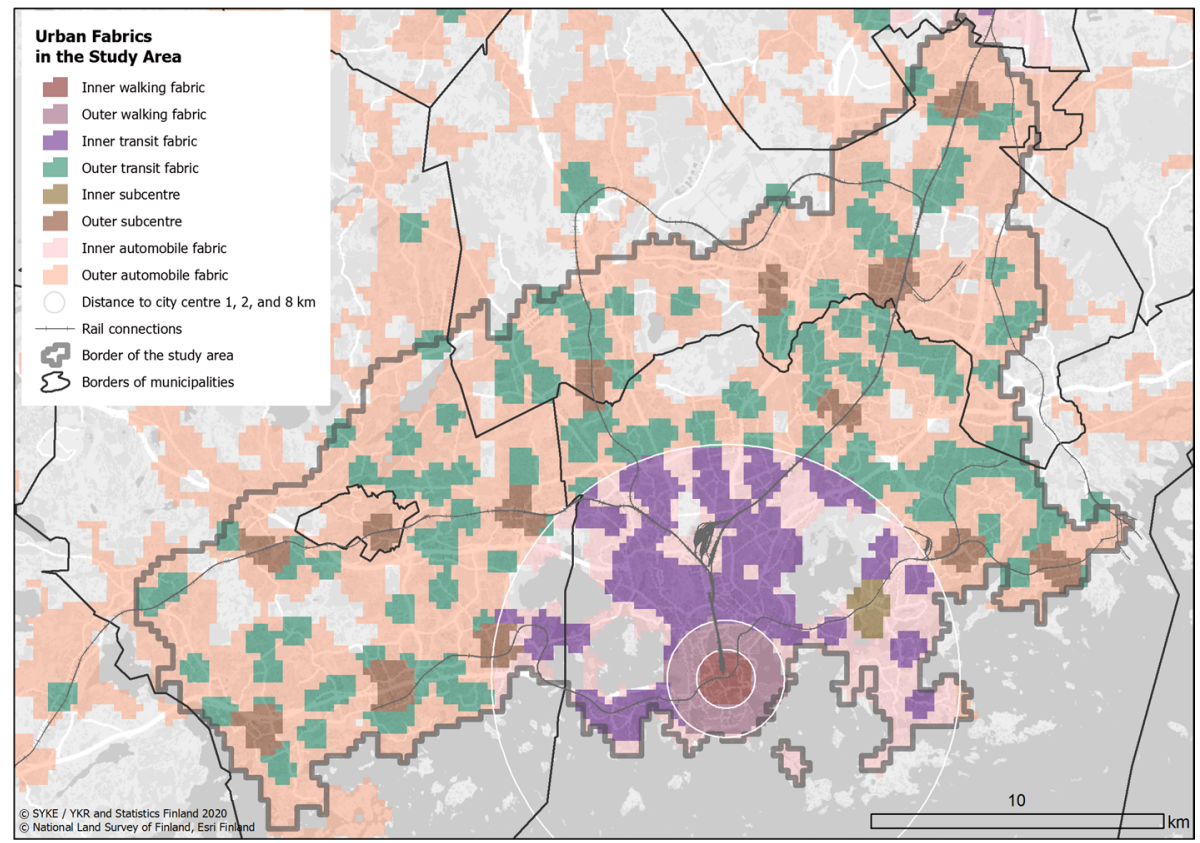

Fig. 1 Urban fabric areas in the core area of HMA (broader grey line marks the border of our case study area)

individually for each of the three subsets by calculating the distributions for sex (male/ female) and age (in five age groups). The age and sex distributions of the survey respondents were matched with the actual distribution in HMA core area using YKR data as a reference.

\section{Variables for car ownership and carlessness}

Table 1 presents the key variables and their explanations regarding car ownership and carlessness based on previous literature. The variables used in our study are also indicated in Table 1, and presented in detail below as car ownership, accessibility, neighborhood, and socio-demographic variables. Household density, commute time, street block density, income, disabilities, car availability, car-share membership, and carpooling were not included in our analysis due to lack of data or existing overlap with other applied variables.

Car ownership. Car ownership was our main response variable. It was classified into three categories: 0, 1, or multiple cars in a household. Accessibility variables. To describe the accessibility and public transportation supply of the respondents' residential environment we applied: Euclidean distances to the closest grocery store, to the closest elementary school, and to the closest green space; the number of public transportation services during rush hour; and Euclidean distance to the city center in kilometers and time distance to city center with various travel modes using the Helsinki Region Travel Time Matrix dataset (Tenkanen et al. 2018). Neighborhood variables. In order to investigate the residential environment of the respondents, we also analyzed the 


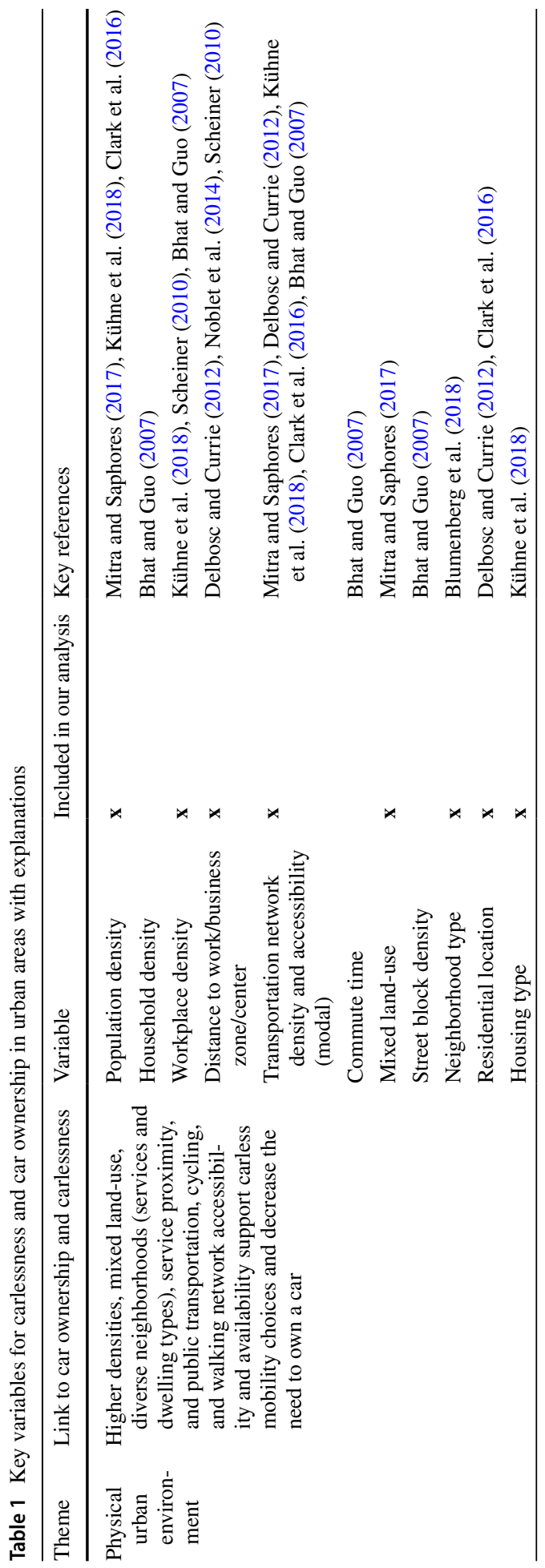




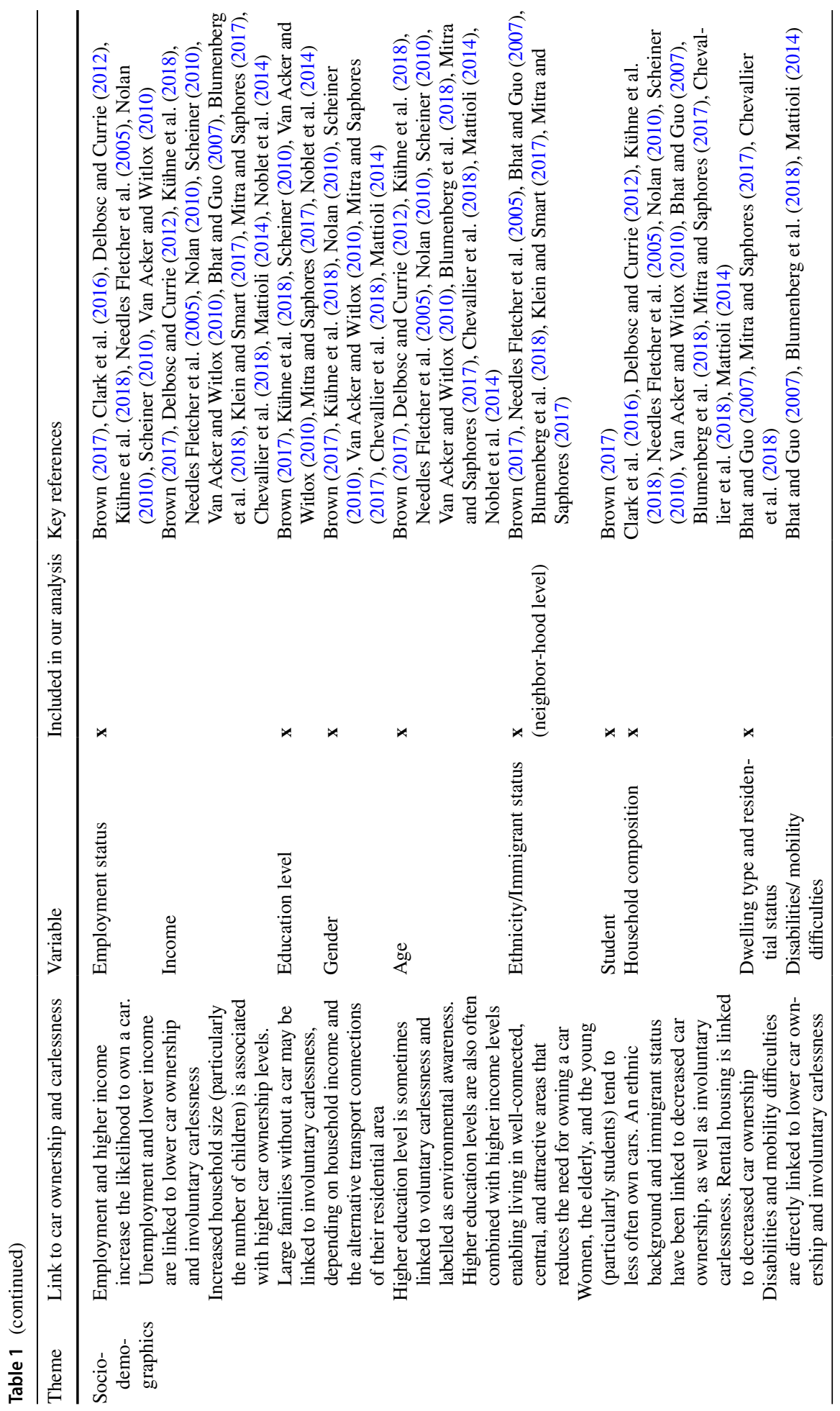




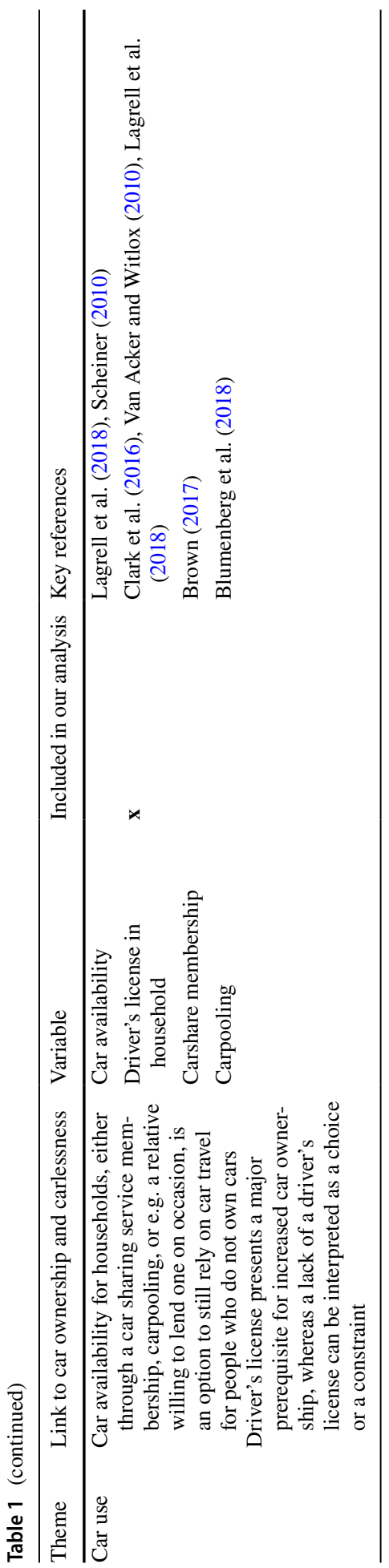


qualities of the surrounding neighborhood mostly calculated as focal sums for the 250-m grid (thus creating an area of $750 \times 750 \mathrm{~m}$ ). These variables were population density, job density, mix of population and workplaces, proportion of apartment buildings, proportion of row houses, proportion of detached houses, homogeneity of house types, proportion of rented apartments, proportion of non-native languages, proportion of carless households, proportion of 1-car households, and proportion of multiple-car households. It is to be noted that the car ownership variables calculated this way describe the overall car ownership in the neighborhood, not the car ownership of individuals or households. Socio-demographic variables. The socio-demographic variables used in the analyses included age, sex, job status, profession, household size, house type, education, second home ownership, and driver's license ownership. Income level was available for less than half of the observations and was hence excluded. Instead, level of education and second home ownership were used as proxies of household affluence. These variables were retrieved from the NTS data (Traficom 2018). See Appendix for detailed variables.

In order to explore the voluntary and involuntary aspects of household carlessness amongst the population in different urban environments, we established three sets of key descriptive variables as criteria based on urban fabrics typologies and existing carlessness literature to potentially detect different types of carlessness related to choice and constraint (Table 2). The voluntarily carless were characterized through increased affluence proxies (higher education level, higher profession, second home ownership), having a driver's license, and living in central and accessible places (walking and transit urban fabrics). For the involuntary carless, the indicators were less affluent (lower education level, lower profession, no second home ownership), younger or older age, and living in less central and accessible places (transit and automobile urban fabrics). The involuntarily carless group is more difficult to identify with confidence since the data does not contain the reasons for not owning a car, and thus we rely on previous research that sheds light on the key variables. However, identifying vulnerable groups within the involuntarily carless is clearer when combining zero car with residential locations in the automobile urban fabric. Additionally, not having a driver's license combined with lower affluence levels can potentially indicate vulnerability as it creates full dependency on public transportation accessibility or central living-both presenting high-demand locations with increasing costs of living in the study area.

\section{Factor analysis and latent class analysis}

In order to simplify partly collinear information in the accessibility, neighborhood and socio-demographic factors, two approaches were utilized. First, we used Exploratory factor analysis $(F A)$ with maximum likelihood and varimax rotation to reduce accessibility and neighborhood variables to only the key factors representing major patterns in the variation. The svyfactanal function (R-package survey) developed for weighted data was applied, and Bartlett scores were defined with the factor.scores function (R-package psych). Overall Measure of Sampling Adequacy (MSA) was tested with Kaiser-Meyer Olkin (KMO) test. Also, Bartlett's test of Sphericity was used to detect whether there was enough correlation between variables. Eigenvalues were used for selecting the number of factors in the analysis. FA was run for the whole data and separately for each urban fabric.

Second, Latent class analysis (LCA), also known as latent structure analysis, was used for classification of households based on categorized socio-demographic variables. We utilized function poLCA (R-package poLCA) with nrep $=10$ in order to estimate the 


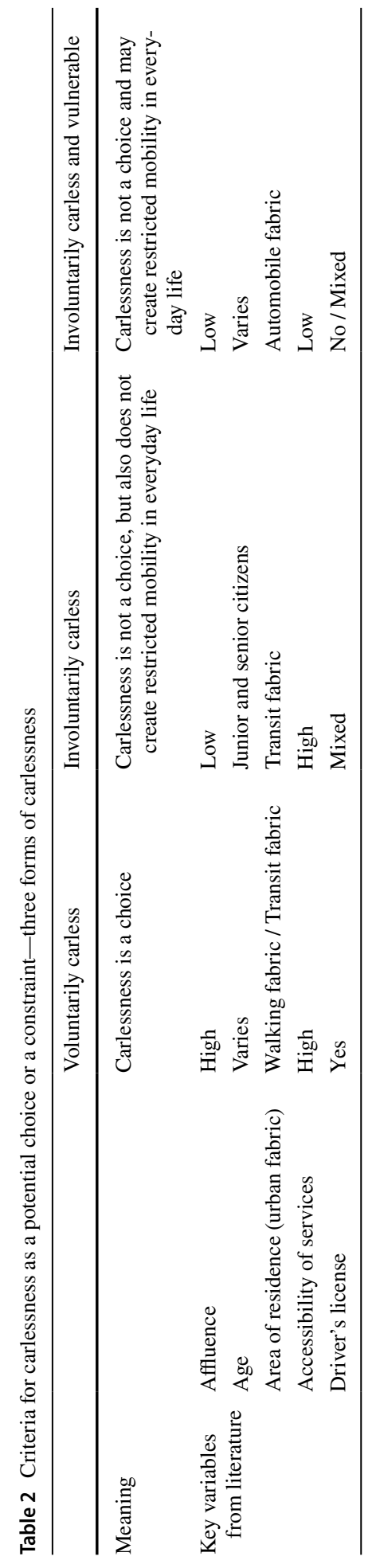




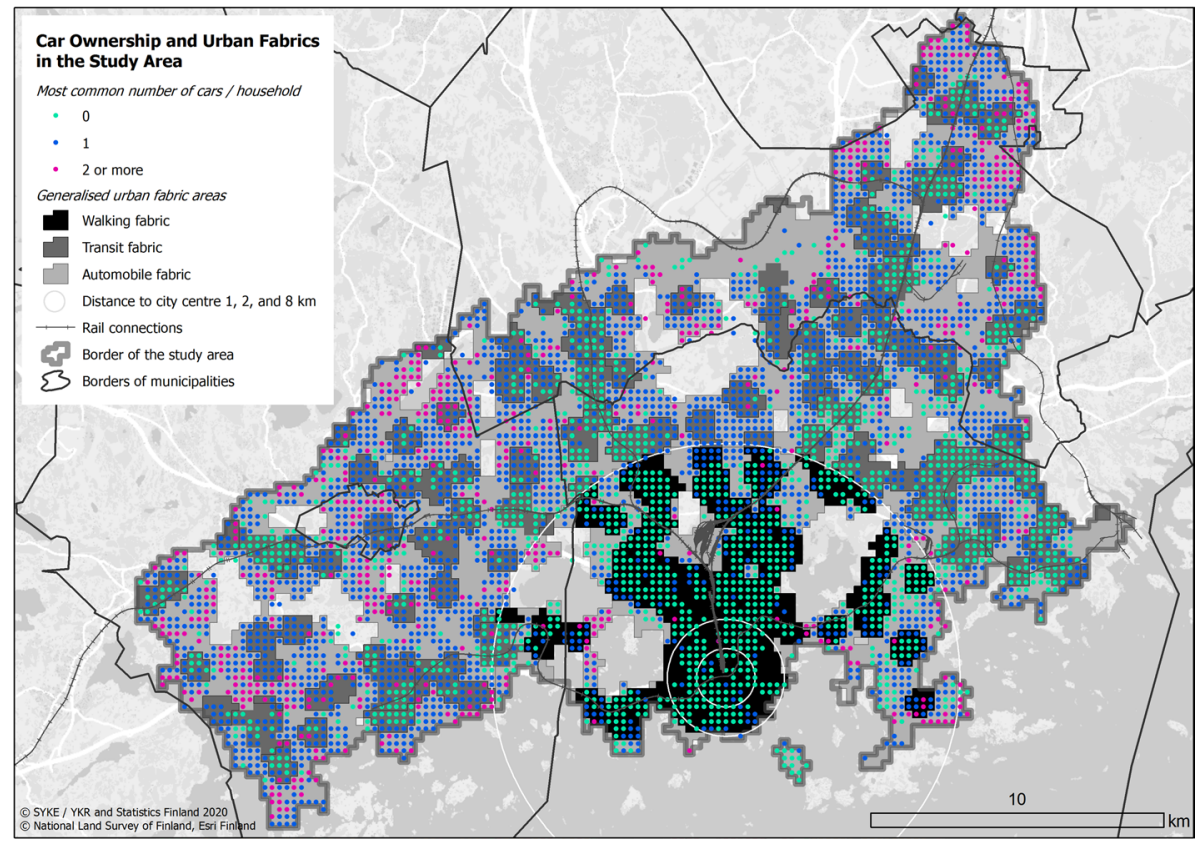

Fig. 2 Car ownership illustrated based on the areas of generalized urban fabrics in the HMA core area. The urban fabrics in this map are generalized from 8 spatial classes to 3 classes from the classification of urban fabrics presented in Fig. 1 for improved legibility of the results and to ensure a statistically adequate number of NTS respondents in each spatial class

global maximum. LCA was done separately for all respondents and again for only the carless households. Factor scores were extracted from each FA in order to explore associations between factors, car ownership, and the LCA groups. The association between the factor scores and household car ownership was tested with Analysis of Variance (ANOVA; function aov), and Tukey's test was used as a post hoc test to define significance of each comparison (function TukeyHSD). Same approach was applied for testing association between factor scores and LCA groups defined for carless households. The associations of car ownership with LCA groups and urban fabrics were tested with Chisquare test (function chisq.test in base $\mathrm{R}$ package statistics). Logistic regression (function glm in base R package statistics) was used to test whether both LCA groups and factor scores explain car ownership. All analyses were run in $\mathrm{R}$ version 3.6.2.

\section{Results}

\section{Spatial distribution of household car ownership}

Car ownership significantly varies across the HMA core area. Figure 2 and Fig. 3 display the distribution of car ownership in relation to the three urban fabrics. As expected, carless households represent the majority of households in the walking urban fabric. 


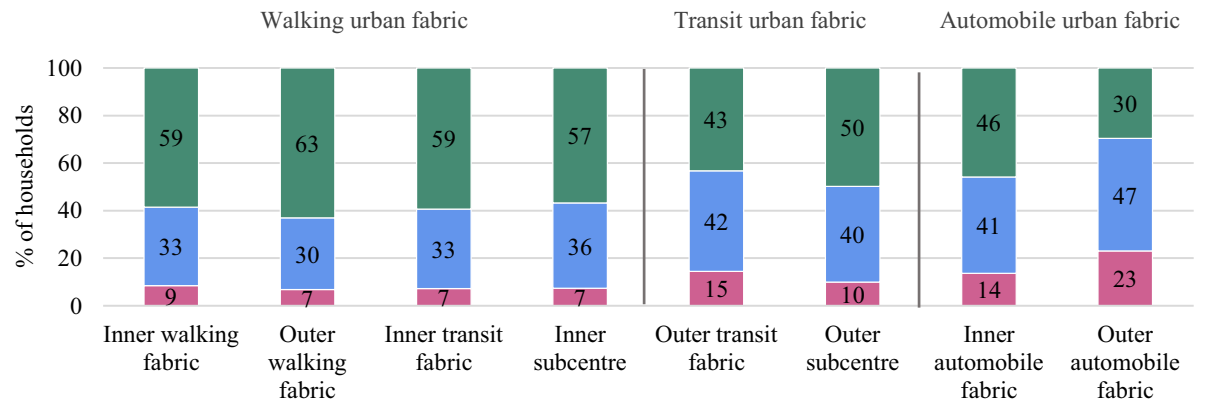

- Share of households with 2 or more cars $\quad$ Share of households with one car $\square$ Share of carless households

Fig. 3 The distribution of carless, one-car and multiple-car households within the different urban fabrics in the HMA core area. Due to rounding, some columns may total $99 \%$ or $101 \%$. The vertical lines represent the generalized reclassification of the urban fabrics (walking, transit, automobile) used in the statistical analyses to ensure a statistically adequate number of NTS respondents in each spatial class. (Sources: SYKE/YKR and Statistics Finland 2014, 2016, and 2017, and A. C. Nielsen retail register 2016)

Carlessness is slightly more common in the transit urban fabric than in the automobile urban fabric, particularly compared to the outer automobile fabric. The automobile fabric also clearly demonstrates an increase in multiple-car ownership.

\section{Influential urban environment features for household car ownership}

FA was applied to explore and identify the main features of the urban environment that influence car ownership in the study area as a whole and separately for each fabric (Table 3, Supplementary Tables S1-S3). The data were adequate for FA according to the KMO test (larger than 0.7) in all datasets, and variables had enough correlation according to the Bartlett's test of Sphericity. Based on the Eigenvalue of each factor, three factors emerged. Altogether, these factors explained $67 \%$ of the variation in the variables in the whole data (Table 3).

Factor 1 was titled as Increasing distance and decreasing density. It reflects the growing distances to the city center in general, by bicycle, and on foot, as well as longer travel times to the center by private cars or public transportation. Additionally, this factor describes the decreasing density of both population and workplaces. Factor 2, labelled as Increasing detached house and decreasing apartment building proportions, indicates an increased proportion of detached houses and a decreased proportion of apartment buildings in the area. In addition, increasing distances to services, such as grocery stores, an increasing proportion of households with cars, and decreasing proportions of rented apartments and non-native languages in the population stand out. Hence, Factor 2 not only captures the physical environment but also the indicators of socio-demographics of the area. Factor 3 , titled Decreasing house type diversity, shows increasing homogeneity of house types that indicates a low mixture of detached houses, apartment buildings, and row houses in the area. On the factor, the proportion of row houses was low, which indicates that the areas with lots of row houses have generally more mixed housing stocks. Factor 3 consisted of only two variables but was still accepted as a factor since the proportion of row houses was clearly connected to the homogeneity of house types. 


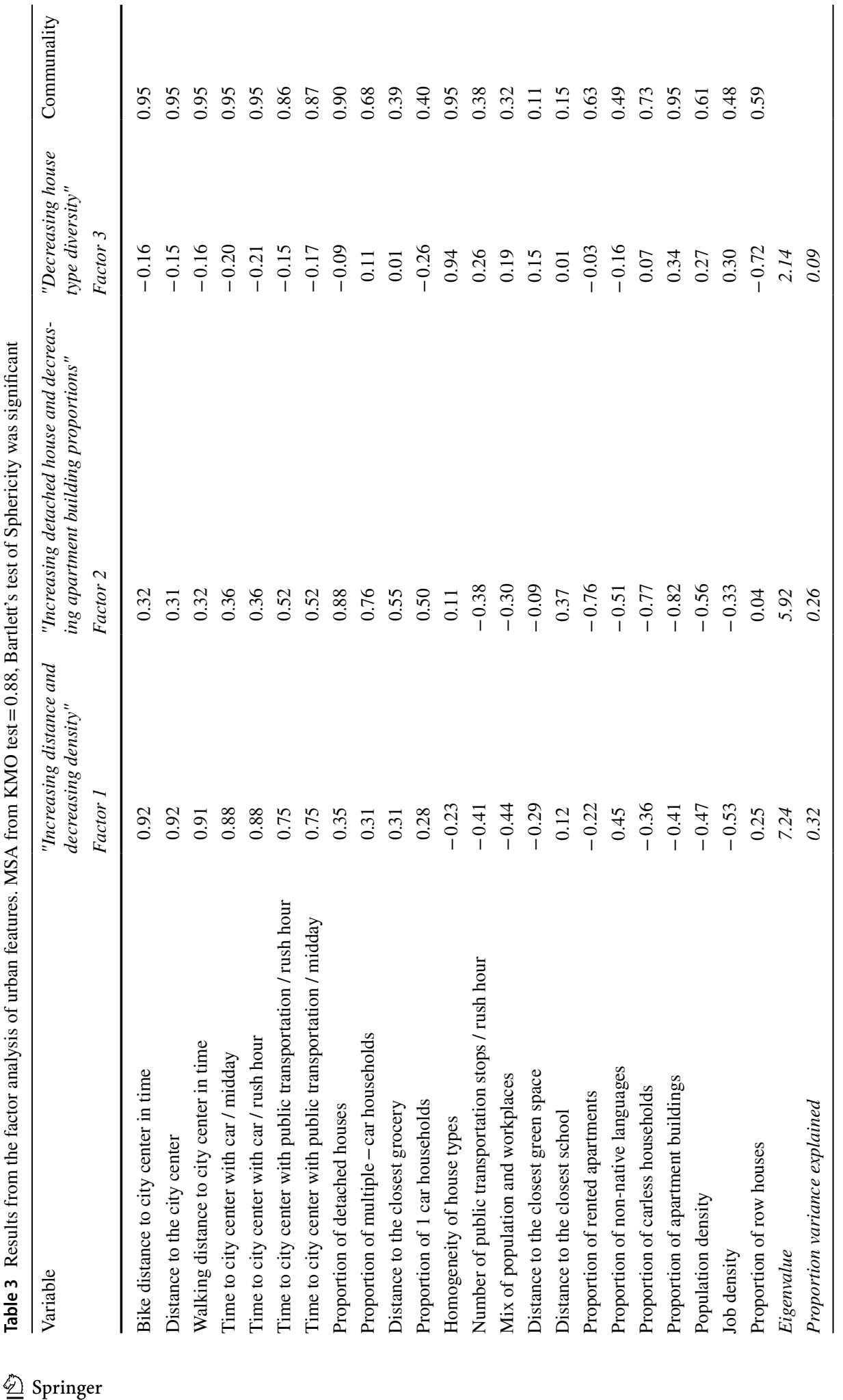


FA for each urban fabric produced corresponding results to the ones described above, yet a few interesting differences reflecting variation between the fabrics were discovered. In all fabrics, the first factor indicated increasing distances and travel times to the city center (Supplementary Tables S1-S3), but only in the walking urban fabric the decreasing density played a role while density was unimportant in the transit and automobile urban fabrics. In terms of Factor 2, the walking urban fabric did not show any association with the socioeconomics of the area, contrary to the transit and the automobile urban fabrics. Moreover, the third factor in transit and automobile urban fabrics matched with the overall results, while in the walking urban fabric only the increasing proportion of row houses was slightly influential. Due to association with just one variable, Factor 3 should not be over-interpreted regarding the walking urban fabric.

Next, we investigated the association between the factors and household car ownership in the entire study area and separately in each urban fabric. In order to do so, the factor scores of each observation were extracted and tested against households with no cars, one car, or multiple cars (Fig. 4). We discovered that the scores of all factors displayed significant variation between 0 and 1, and multiple-car households in the whole study area (ANOVA, all comparisons $p<0.001$; Fig. $4 \mathrm{a}-\mathrm{c}$ ). Households with one or multiple cars had higher factor scores regarding all factors. In other words, increasing distance and decreasing density (Factor 1), increasing proportion of detached houses and decreasing proportion of apartment buildings of the area (Factor 2) as well as decreasing diversity of house types (Factor 3) were associated with car owning households in the study area.

The associations between car ownership and the factors appeared much stronger at the HMA level than within the individual fabrics. Interestingly, no factor showed significant association with car ownership in the walking urban fabric (Fig. 4d-f). Also, in transit and automobile urban fabrics the associations between the car ownership and factors were less pronounced when compared to the whole data. This indicates that within the fabrics, the carless and car-owning households are exposed to rather similar features of the urban environment. However, both in transit and automobile urban fabrics, an increasing proportion of detached houses and the decreasing proportion of apartment buildings in the living area (Factor 2) were significantly different between the 0,1 , and multiple-car households (ANOVA, all comparisons $p<0.001$; Fig. 4g-1). Moreover, in the automobile urban fabric, the increasing distance and decreasing density (Factor 1) showed mild, but significant association with increased car ownership (ANOVA, all comparisons $p<0.03$; Fig. 4j), and the house type diversity (Factor 3 ) was significantly decreased for the multiple-car households as compared to the one-car households (ANOVA, $p<0.001$; Fig. 41).

\section{Socio-demographic variables associated with household car ownership and carlessness in the urban fabrics}

Next, we studied the association between socio-demographic variables and household car ownership in different urban fabrics. LCA was utilized to classify households based on nine variables (listed in Table 4) and to construct socio-demographic profiles for car ownership. Six socio-demographic groups emerged and were labelled as Lower education singles and couples, Higher education singles and couples, Pensioner couples, Families, Elderly female pensioners, and Students. It is important to notice that each of these groups included variation in terms of the variables, and our short labels are just capturing the most distinctive features of each group. For example, one-person non-pensioner households, 

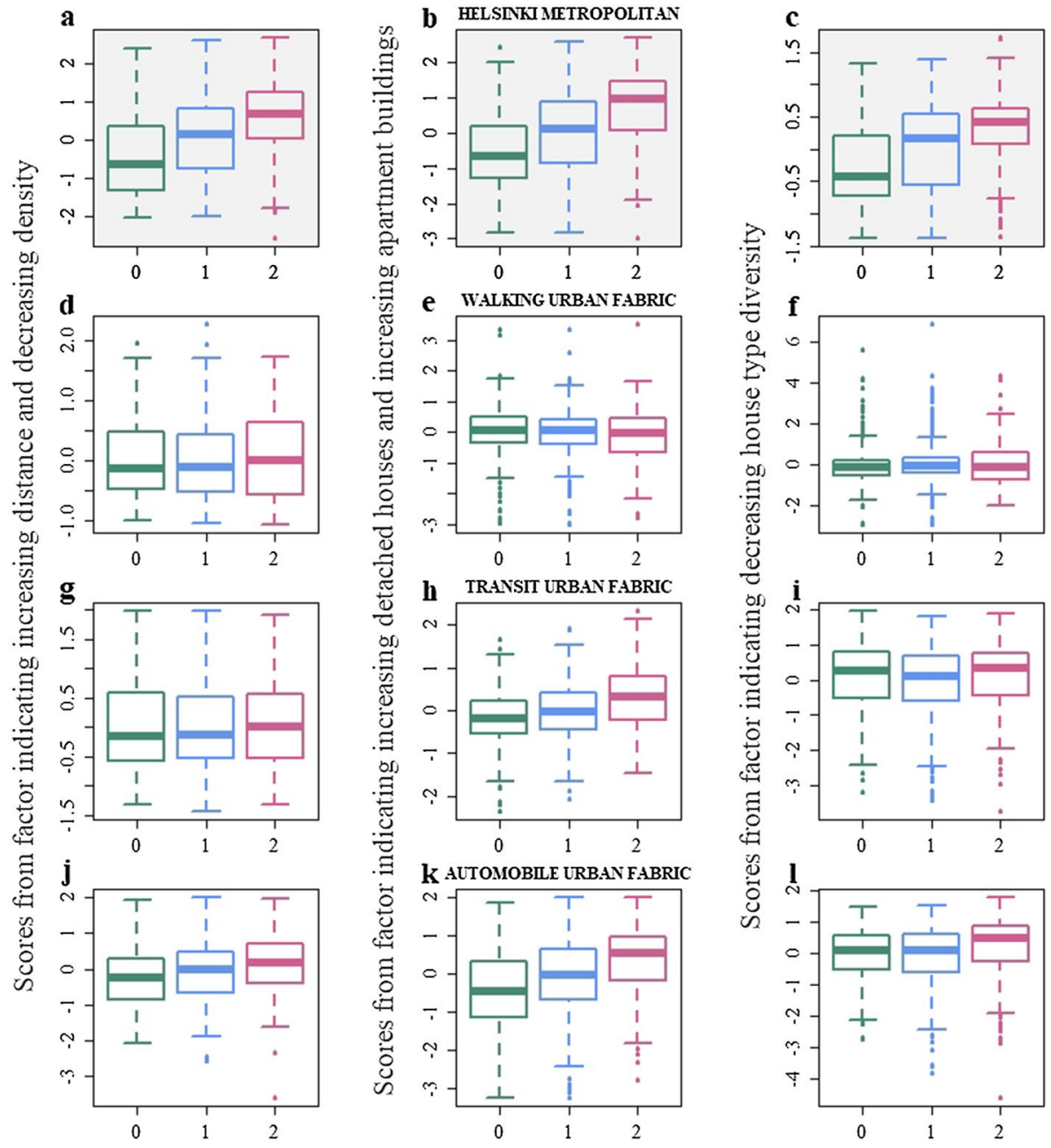

Fig. 4 The association between urban features and car ownership across the HMA urban core area and the different urban fabrics. Results are presented from the four separate analyses for data including all observations, i.e. HMA urban core area $\mathbf{a}-\mathbf{c}$ and for data including only observations from walking $\mathbf{d}-\mathbf{f}$, transit $\mathbf{g - i}$ or automobile $\mathbf{j}-\mathbf{l}$ urban fabrics. Y-axis presents the scores for Factor $1 \mathbf{a}, \mathbf{d}, \mathbf{g}, \mathbf{j}$, Factor $2 \mathbf{b}, \mathbf{e}, \mathbf{h}, \mathbf{k}$ and Factor 3 c,f,i,l. Scores are shown for household without cars (0), with one car (1), and with multiple cars (2). Note that the scores are not directly comparable between different figures because they are from separate analyses and because rotation was utilized in the FA

while prominent in the HMA, do not form a homogenous group of people and are thus distributed across many LCA groups in our analysis.

These groups differed significantly in terms of car ownership (Chi-square test, $\mathrm{X}^{2}=567.27, p<2.2 \mathrm{e}-16$; Fig. 5a). Families were the least likely to be carless, while elderly female pensioners and students represent the opposite. Notably, $100 \%$ of families have a driver's license, while $76 \%$ of elderly female pensioners do not. We also explored the distribution of these socio-demographic groups across the urban fabrics $\left(X^{2}=105.45, p<2.2 e-16\right.$; Fig. 5b). The most pronounced differences were found 


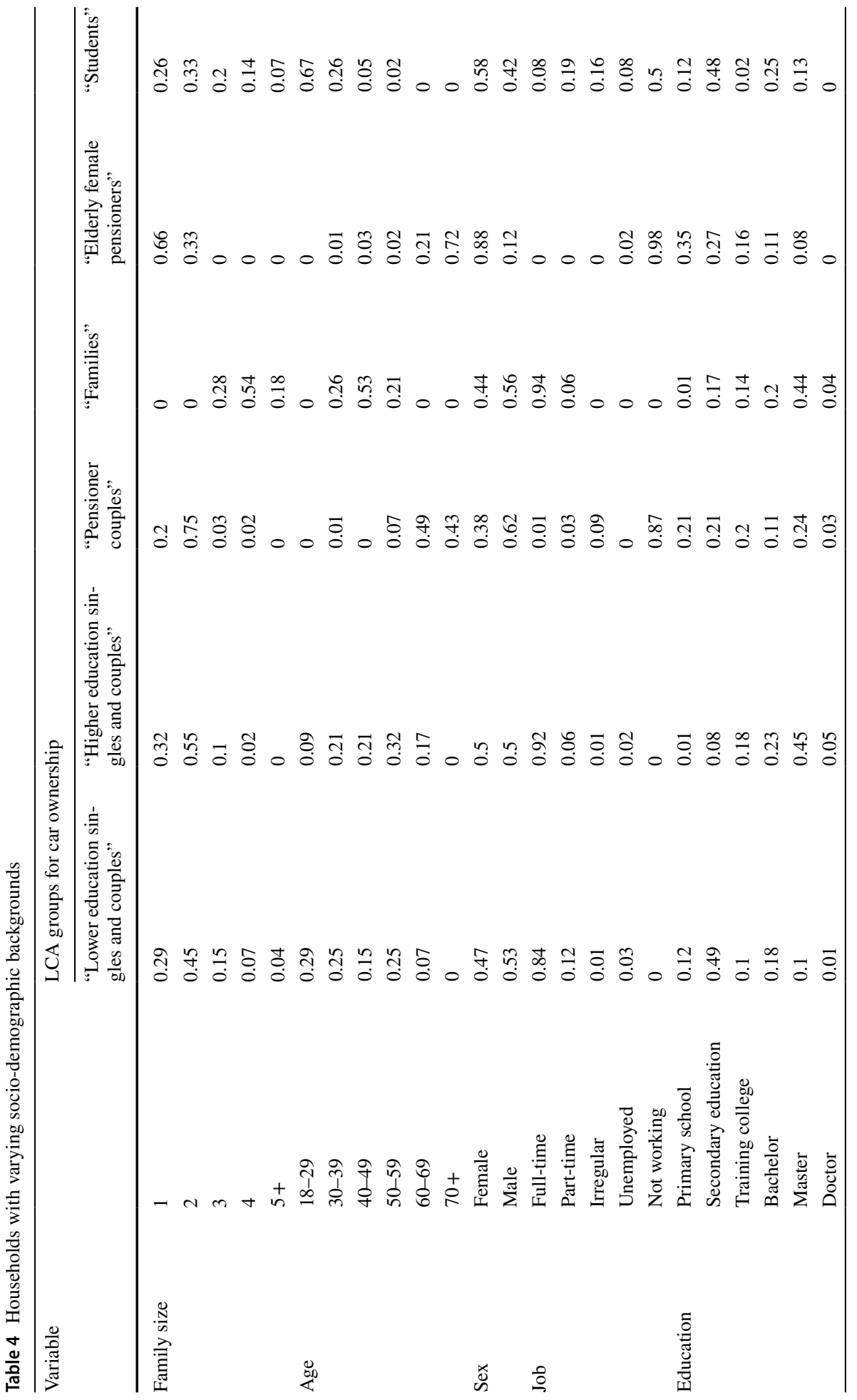




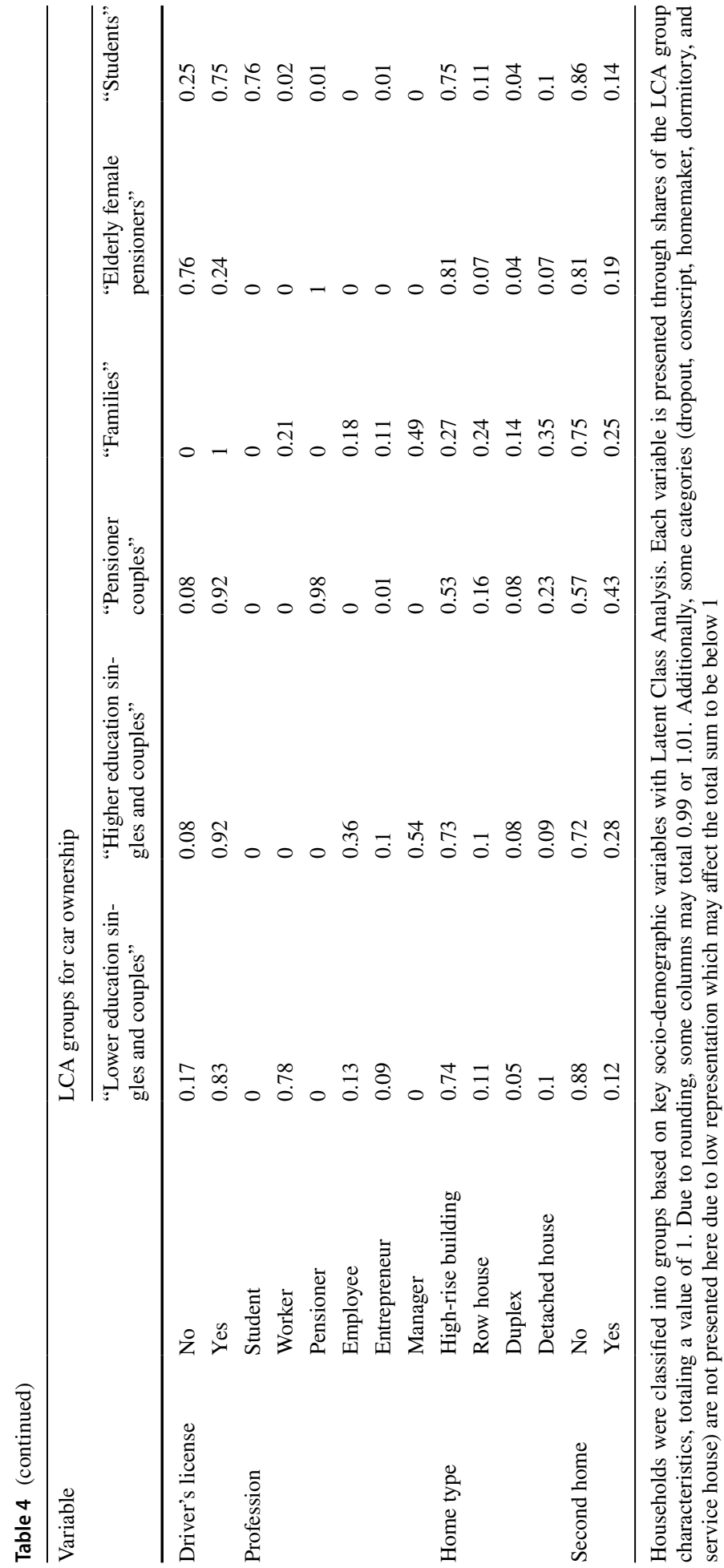



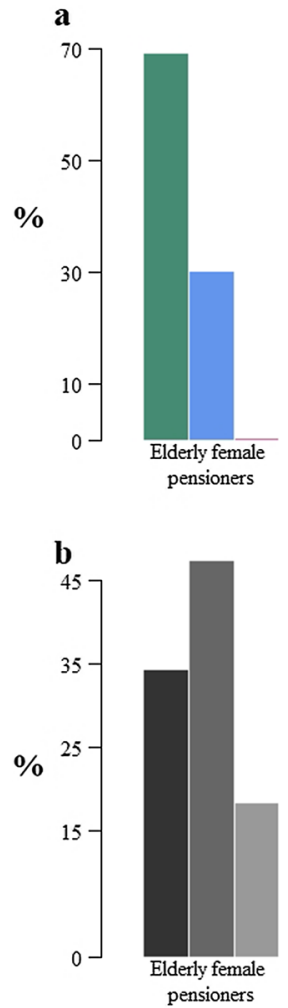
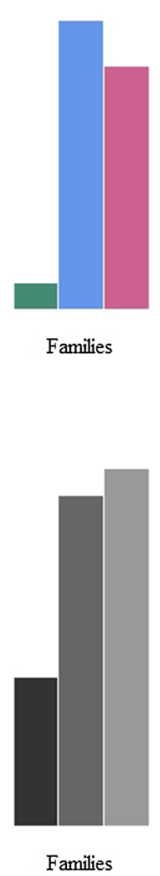
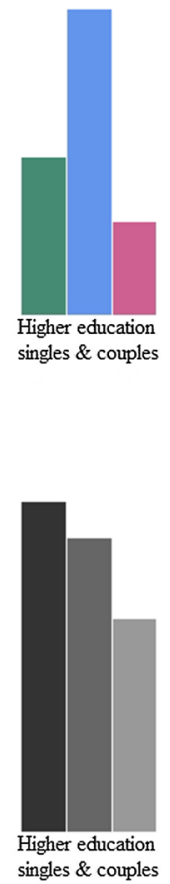

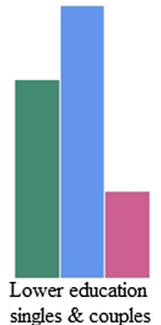

singles \& couples

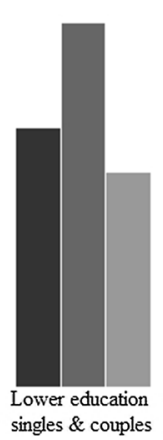

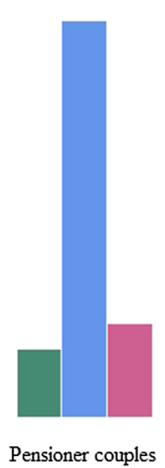

- Zero

- One

- Two

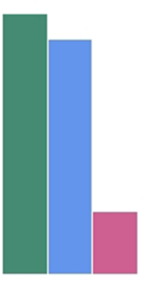

Students

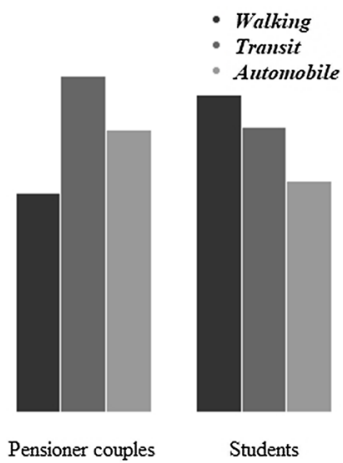

Fig. 5 Car ownership and residential location in urban fabrics of the socio-demographically grouped households. The proportion of car ownership in different socio-demographic groups a, and the proportion of different groups living in each urban fabric b

regarding families, of which only few lived within the walking urban fabric, and regarding the elderly female pensioners of which few resided in the automobile urban fabric. Moreover, a larger proportion of higher education singles and couples were living in the walking urban fabric compared to the lower education singles and couples, who appeared to more frequently reside in the transit urban fabric (Table 4).

\section{Urban environment features and socio-demographic variables in association to car ownership}

The key features of the physical urban environment (factors) and socio-demographics (LCA groups) were studied together to evaluate their integrated influence on car ownership. In this adjusted analysis, the observations were clustered into carless and car-owning households. We found that in the whole study area, both types of features significantly associated with car ownership (Logistic regression, for all variables $p<0.001$ ) and all identified key variables are meaningful (even when their potential parallel effect was controlled for). In other words, in the HMA, socio-demographic features of the household as well as all key features of urban environment i.e. distance to the city center and density of housing 
(Factor 1), proportions of different house types (Factor 2) and diversity of house types (Factor 3) were associated with household car-ownership.

Within different urban fabrics, the socio-demographic features tended to play varying roles when compared with the urban features. In the walking urban fabric, socio-demographics of the households associated with car ownership (Logistic regression, $p<0.002$ ) whereas none of the urban environment features had a significant association in this urban fabric. In both the transit and automobile urban fabrics, the results were corresponding, as the socio-demographics (particularly the life stage) of households associated with car-ownership, while the proportions of house types (Factor 2) also showed significant association (Logistic regression, for all variables $p<0.002$ ). For the automobile urban fabric, the distance to the city center and density of housing (Factor 1 ) showed also association with car ownership (Logistic regression, $p=0.002$ ).

\section{Analyses on carless households}

Carless households were further looked into, as we wanted to better understand the potential representations of voluntary and involuntary aspects of carlessness in our study area. Criteria for identifying varying types of carlessness was established based on previous literature and the urban fabrics typologies (Table 2) and utilized as a lens for exploring the results produced in the following analyses.

The carless households were classified with LCA (Table 5) resulting in the following four groups: Lower education singles and couples, Students, Elderly female pensioners and Higher education singles and couples. Once again, it is important to notice that groups included variation beyond these descriptive labels. The labels applied here are the same as for car ownership, but the distributions of variables within the groups slightly differ from the entire sample. For example, one-person households are more common in both lower and higher education singles and couples groups than for the entire sample of households. Additionally, second home ownership, usually signifying a countryside summer cottage, is lower in each group, as compared to Table 4, and is used as a proxy for increased affluence. Considering the presence of driver's license is also a key determinant in terms of carlessness as a choice or a constraint, as established in Table 2.

We then explored the distribution of different carless household groups in the different urban fabrics and discovered significant differences (Chi-square test, $X^{2}=37,906$, $p<0.001$; Fig. 6a-b). Firstly, the number of carless households was clearly smaller in the automobile urban fabric compared to other areas (Fig. 6b). Secondly, higher education singles and couples were found in higher proportions within the walking urban fabric, while the elderly female pensioners were more likely found in the transit urban fabric. The proportions of different groups did not differ much between the urban fabrics besides the aforementioned trends (Fig. 6a).

We further studied whether the features of the urban environment (factors) influenced the identified carless groups differently (Fig. 7). We discovered that the relationship between urban features and carless groups was very similar in lower education singles and couples, and students, while the elderly female pensioners and higher education singles and couples differed greatly from one another (ANOVA, all comparisons $p<0.001$ ). Higher education singles and couples were significantly more likely to have shorter distances to the city center and live in areas of high density (Factor 1), to live in areas of higher proportion of detached houses and decreasing proportions of apartment buildings (Factor 2), 
Table 5 Socio-demographic groups of carless households

\begin{tabular}{|c|c|c|c|c|c|}
\hline \multirow[t]{2}{*}{ Variable } & & \multicolumn{4}{|c|}{ LCA groups for carless households } \\
\hline & & $\begin{array}{l}\text { "Lower education } \\
\text { singles and couples" }\end{array}$ & "Students" & $\begin{array}{l}\text { "Elderly female } \\
\text { pensioners" }\end{array}$ & $\begin{array}{l}\text { "Higher educa- } \\
\text { tion singles and } \\
\text { couples" }\end{array}$ \\
\hline \multirow[t]{5}{*}{ Family size } & 1 & 0.53 & 0.46 & 0.76 & 0.5 \\
\hline & 2 & 0.34 & 0.38 & 0.23 & 0.32 \\
\hline & 3 & 0.09 & 0.13 & 0 & 0.11 \\
\hline & 4 & 0.03 & 0.01 & 0 & 0.05 \\
\hline & $5+$ & 0.02 & 0.02 & 0 & 0.03 \\
\hline \multirow[t]{6}{*}{ Age } & $18-29$ & 0.34 & 0.75 & 0 & 0.13 \\
\hline & $30-39$ & 0.26 & 0.21 & 0.02 & 0.38 \\
\hline & $40-49$ & 0.15 & 0.02 & 0.02 & 0.3 \\
\hline & $50-59$ & 0.19 & 0.02 & 0.06 & 0.16 \\
\hline & $60-69$ & 0.06 & 0 & 0.27 & 0.04 \\
\hline & $70+$ & 0 & 0 & 0.62 & 0 \\
\hline \multirow[t]{2}{*}{ Sex } & Female & 0.59 & 0.53 & 0.73 & 0.53 \\
\hline & Male & 0.41 & 0.47 & 0.27 & 0.47 \\
\hline \multirow[t]{5}{*}{ Job } & Full-time & 0.82 & 0.11 & 0 & 0.95 \\
\hline & Part-time & 0.13 & 0.2 & 0.01 & 0.02 \\
\hline & Irregular & 0.01 & 0.13 & 0.01 & 0.01 \\
\hline & Unemployed & 0.04 & 0.09 & 0.01 & 0.01 \\
\hline & Not working & 0 & 0.48 & 0.96 & 0.01 \\
\hline \multirow[t]{6}{*}{ Education } & Primary school & 0.09 & 0.11 & 0.39 & 0 \\
\hline & Secondary education & 0.44 & 0.49 & 0.28 & 0 \\
\hline & Training college & 0.13 & 0.03 & 0.12 & 0.03 \\
\hline & Bachelor & 0.21 & 0.25 & 0.09 & 0.2 \\
\hline & Master & 0.12 & 0.12 & 0.1 & 0.67 \\
\hline & Doctor & 0.01 & 0 & 0 & 0.09 \\
\hline \multirow[t]{2}{*}{ Driver's license } & No & 0.37 & 0.35 & 0.72 & 0.09 \\
\hline & Yes & 0.63 & 0.65 & 0.28 & 0.91 \\
\hline \multirow[t]{6}{*}{ Profession } & Student & 0 & 0.91 & 0 & 0 \\
\hline & Worker & 0.72 & 0 & 0 & 0.09 \\
\hline & Pensioner & 0 & 0 & 1 & 0 \\
\hline & Employee & 0.18 & 0 & 0 & 0.25 \\
\hline & Entrepreneur & 0.07 & 0.01 & 0 & 0.04 \\
\hline & Manager & 0.03 & 0 & 0 & 0.62 \\
\hline \multirow[t]{5}{*}{ Home type } & Service house & 0 & 0 & 0.02 & 0 \\
\hline & High-rise building & 0.93 & 0.88 & 0.81 & 0.92 \\
\hline & Row house & 0.03 & 0.05 & 0.07 & 0.05 \\
\hline & Duplex & 0 & 0.01 & 0.03 & 0.01 \\
\hline & Detached house & 0.03 & 0.04 & 0.06 & 0.02 \\
\hline \multirow[t]{2}{*}{ Second home } & No & 0.93 & 0.91 & 0.86 & 0.82 \\
\hline & Yes & 0.07 & 0.09 & 0.14 & 0.18 \\
\hline
\end{tabular}

Carless households were classified into groups based on key socio-demographic variables with Latent Class Analysis. Each variable is presented through shares of the LCA group characteristics, totaling a value of 1 . Due to rounding, some columns may total 0.99 or 1.01. Additionally, some categories (dropout, conscript, homemaker, dormitory, and service house) are not presented here due to low representation which may affect the total sum to be below 1 

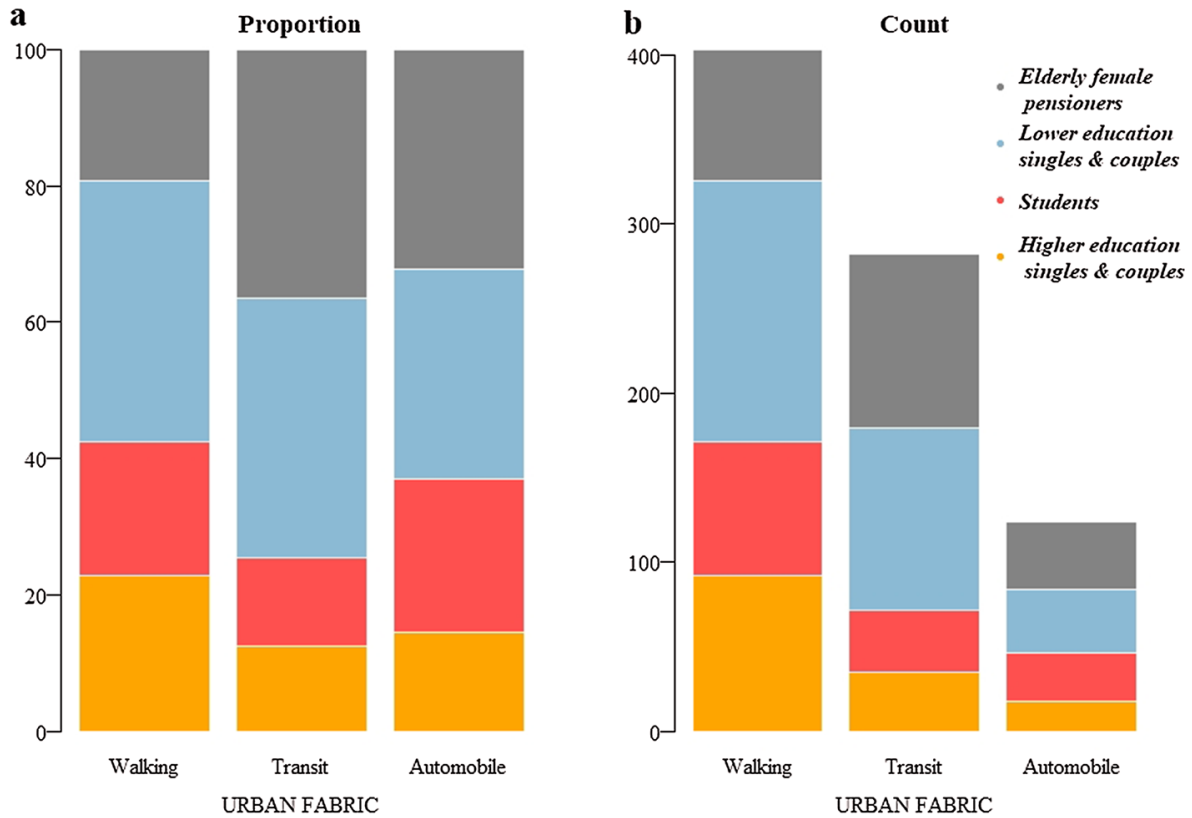

Fig. 6 The proportion a and count $\mathbf{b}$ of carless households based on socio-demographic groups in walking, transit, and automobile urban fabrics
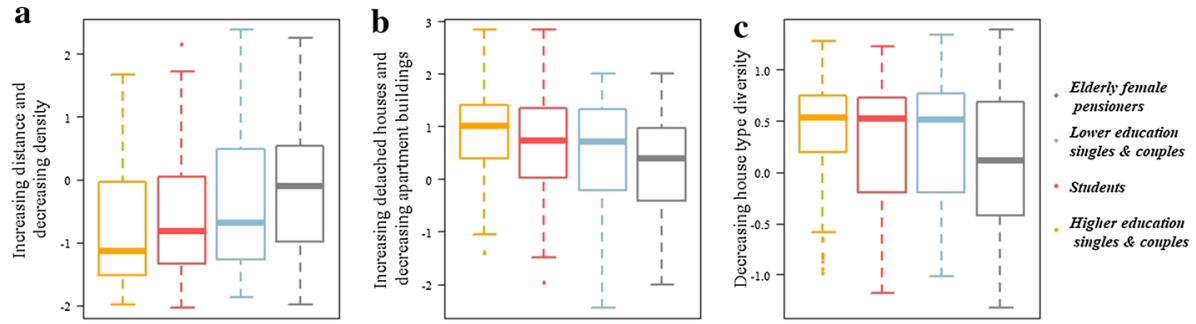

Fig. 7 Association between urban features and carless groups (Factor $1=a$; Factor $2=b$; Factor $3=\mathrm{c})$

as well as to live in areas of lower diversity of house types (Factor 3) than the carless pensioners.

Through combinations of residential location, service accessibility, affluence, age, and driver's license ownership data (Table 2), the voluntary and involuntary aspects of carlessness were explored. Most notably, higher education singles and couples with the economic ability to reside in accessible and central areas, combined with the information that $91 \%$ of these households have driver's licenses, indicates carlessness as a choice. This household group clearly differs from the other carless households that are less affluent, residing in less accessible residential locations (particularly in the automobile urban fabric), or residing in accessible yet expensive areas which creates an economic strain in terms of housing expenses, and possess significantly less driver's licenses. As established, these households present a tricky group regarding certain identification of carlessness as a choice or a constraint since they mostly reside in the accessible walking and transit fabrics. For some, 
carlessness may not be restrictive of their mobility but for some it may be, particularly in the outer transit fabric. For example, the elderly female pensioners appear especially vulnerable alongside a proportion of lower education singles and couples residing in the automobile urban fabric. Students represent an interesting group that may still be residing with their parents or in supported student housing in central and accessible areas. Notably, each carless group does include some households within the automobile urban fabric.

\section{Discussion}

In this paper, we have studied zero-, one-, and multiple-car households in different urban fabrics in the Helsinki Metropolitan Area urban core, Finland, regarding where they are located, who they are, and what urban and socio-demographic characteristics are influential to these discoveries. The integrated analysis presented here combines the spatial and social features for the first time in an exploration of urban carlessness and car ownership variation. This study contributes to the currently narrow urban carlessness research, particularly within the European context, and in a novel manner utilizes the urban fabrics thinking to explore and discuss chosen and constrained carless lifestyles across different urban environments. It provides a strong platform for many future research directions as highlighted throughout this Section.

Our results corroborate the previous findings in literature regarding the importance of both physical urban features and socio-demographics to varying levels of car ownership as well as characteristics for different types of carlessness, and most importantly statistically disclose their significance and influence in relation to one another. Overall, the increasing distance to the city center, decreasing densities, increasing proportions of detached houses and decreased proportions of apartment buildings, and a decreasing house type diversity are linked to increased household car ownership in our case area. We also find that larger household sizes are linked with increased car ownership whereas younger and older age more likely indicate carlessness (see e.g. Clark et al. 2016; Blumenberg et al. 2018). Out of a diverse set of features and variables available in literature, the applied methodology allows us to detect the key determinants for our study area - an approach that is applicable to other urban areas, as well. We argue that the carless population, and in particular the aspect of choice or constraint, requires increased attention, both in academia and in practice, as it enables us to identify successful urban planning in terms of sustainable and physically active mobility, as well as persisting vulnerabilities and inequities in urban areas.

While the integration of the two different datasets enabled a novel approach to urban carlessness research, it also required choices and reorganization of data. In particular, the NTS sample size dictated the level of detail in terms of the urban fabric subsets. Instead of analyzing the initial eight classes available through YKR data, they were combined to form three subsets to ensure adequate observations for further analyses. However, relying on the three subsets was eventually deemed better for increased legibility of the results. Some key variables were not included in the analysis due to either unavailable or limited data. Most notably, income as such was excluded from our analysis, yet several other proxies for affluence remained available. Lastly, with these quantitative datasets we were unable to touch upon individual behavior, values, preferences, or motivations, that also influence mobility choices, and are thus essential objectives for future research. 


\section{Physical urban environment features-a foundation for the carless lifestyle}

Our results reveal that the distribution of household car ownership varies greatly across the HMA urban core, while showing little variation in terms of influential factors within a specific urban fabric. The three fabrics represent varied living environments, functions, and opportunities for households and set the outline for their mobility choices (Newman et al. 2016), which is clearly visible in our results. This indicates the importance of physical urban form in terms of car ownership alongside the urban fabrics classification providing a successful framework for categorizing our cities.

While the urban fabrics offer different opportunities for mobility choices and the related lifestyles, they are not equally available to everyone. In the HMA, like in most European metropolitan areas, the demand for centrally located housing is extremely high, which has led to high living costs (Marttinen 2020; Vandecasteele et al. 2019). Our results show that living in the densest, most connected, and accessible central area is not the case for all carless households, even if the urban environment of the walking fabric most effectively supports such lifestyle. However, many carless households are located further away in the transit fabric, and in some cases even in the automobile fabric. We speculate this is to a great extent caused by the rising costs of housing in the central and high-accessibility areas - a phenomenon also identified by e.g. Chevallier et al. (2018) in the French metropolitan areas. Thus, an important issue to consider both in terms of new development and redevelopment of existing neighborhoods through densification, is the economic accessibility of housing. It can be assumed that the population growth within the HMA continues and the demand for well-connected and central housing is only expected to increase (Vuori and Kaasila 2020). This creates further pressure for spatial planning and policies aimed at ensuring that the housing market does not outprice the population, particularly those who are dependent on public transportation. Our findings further emphasize the importance of integrated land-use and transportation planning at the regional and local levels, and the development of sub-centers and rail station surroundings. They can provide options to expand the walking and transit fabrics further into the automobile city, thus transforming the local functions and lifestyles and providing opportunities for sustainable mobility.

Future research is needed to better understand the links between mobility choices and residential locations, and in particular the economic constrains related to these choices. The ways in which mobility choices and patterns may develop in the future due the new sub-centers, as well as new technologies, e.g. car sharing, e-cars, and driverless cars, need to be analyzed further, as called for by Tuominen et al. (2019). Additionally, the micro scale urban design that supports walking, cycling, and the use of public transportation, requires further analysis. This includes acquiring better understanding of transportation nodes, multimodality, and inter-modality, and integrating the larger scale metropolitan understanding of transportation trends with smaller scale attractive local urban design to more effectively plan for the future and reach the set regional goals of sustainable and just transportation systems.

\section{Who owns a car and who is carless in the HMA?}

Our results indicate that car ownership divides the HMA households into six key groups: singles and couples with lower education levels, singles and couples with higher education levels, families, elderly female pensioners, pensioner couples, and students. These groups are labelled according to the main socio-demographic traits they 
represent. It should be noted that although the number of single households in the HMA is significant and continues to rise, they do not form a homogenous group and are thus distributed amongst the groups (Terämä et al. 2018). The results show that families are nearly never carless and represent the least likely group to live without a car, thus confirming previous findings (e.g. Clark et al. 2016) regarding increases in household size, and particularly the presence of children, having a link to increased car ownership. Interestingly, pensioner couples represent another group who is more likely to own a car than not, while on the contrary the elderly female pensioners are highly likely to be carless. The latter group is significantly older than the pensioner couples, born mainly in the 1930's and 1940's, and likely not having ever acquired a driver's license. This finding indicates that even post-retirement, changes in household size and ageing affect car ownership. Additionally, these two groups of pensioners also differ in terms of wealth-a trait notably linked to increased car ownership in previous literature (e.g. Brown 2017; Mitra and Saphores 2017; Chevallier et al. 2018)-and it is also echoed in their residential preferences as the older and less affluent single pensioners tend to live in the more affordable transit fabric more often than their pensioner couple counterparts.

When looking into carless households specifically, we discovered that carlessness is most common amongst lower education singles and couples, students, elderly female pensioners, and higher education singles and couples. Whether or not this carless lifestyle is a choice or a constraint, our statistical analysis that allows for comparison first, between carowning and carless households, and second, between different carless households identifies the same key characteristics and trends related to voluntary and involuntary aspects of carlessness as previous qualitative or survey-based literature (e.g. Kühne et al. 2018; Mitra and Saphores 2017; Brown 2017; Lagrell et al. 2018). Affluent households and central residential locations are thus more likely linked to chosen carlessness, while less affluent households with a reduced chance to choose their residential location in the most accessible (and thus most expensive) areas are potentially involuntary carless yet not always restricted in their mobility. Since more than $90 \%$ of the carless higher education singles and couples have driver's licenses (while that number for other groups is approximately $60 \%$, and less than $30 \%$ for the elderly female pensioners), the carless lifestyle combined with higher education levels, high-end professions resulting in higher incomes, and the ability to live in central and accessible areas strongly indicates it being a choice. Such a group of highly educated, affluent, small households has been identified as an 'outlier' in terms of car ownership and increased affluence in previous literature as well, and they have been referred to as voluntarily carless and environmentally aware (Brown 2017; Lagrell et al. 2018). However, we recognize that other motivations to be voluntarily carless most likely exist beyond the environmental concerns, possibly mere urban lifestyle with high-quality services within walking distance, and the opportunity to use mobile devices in public transportation, which changes the time in travel from a cost to a commodity. Nonetheless, this is clearly a very different group from the other carless households, and particularly from the elderly single pensioners who are potentially involuntarily carless due to a lack of a driver's license combined with lower incomes and more remote residential locations, at times even in the automobile fabric. Our results clearly identify a large vulnerable group of less affluent elderly women and a dependency on alternatives to the automobile, or others (Mattioli 2014), throughout the HMA core area. In general, female representation is slightly higher amongst the carless households as compared to all households, also aligning with previous research that has found women more likely to be carless (e.g. Mitra et al. 2017; Nolan 2010; Mattioli 2014). As for the future, the current elderly generations will be deceased, and the next elderly generation takes over. We might speculate that a change in this respect 
is probable by 2030, since the females born in the 1950's have more driver's licenses than the previous age cohorts. In addition, we may expect that future male pensioners will live longer which again might result in decreased involuntary carlessness in this group.

The results related to the urban environment features, the socio-demographic household groups, and car ownership and carlessness, can also be used to formulate trends regarding the living situation, mobility choices, and vulnerabilities of the metropolitan population throughout their life course. Young students tend to live in financially supported student housing, located in the walking and transit fabrics, and they are mostly carless by choice, or at least not suffering from restricted daily mobility, due to their accessible residential areas. Similarly, the majority of the lower education singles and couples reside in the walking and transit fabrics. The availability of less expensive apartments is higher in the transit fabric, and thus tend to drive the less affluent households to reside in these areas. Contrary to the lower education singles and couples, the more affluent higher education singles and couples tend to reside in the more central and expensive walking fabric. With increasing household sizes, we clearly see a trend of families (rarely carless) residing in the automobile and transit fabrics with lower densities and a higher dependency on car travel. The retired population is distributed across the urban fabrics but depending on their affluence and ability to drive raises questions related to adequate accessibility and equity.

We thus argue that the choice of residential locations is not dictated by the availability of transportation mode choices, but largely by affluence and the availability of suitable housing, that reflect the changing situations over a course of a life. By further studying the timeline of household car ownership, we could pinpoint the exact situations that lead to increased or decreased car ownership in detail. Studying carless households provides essential information on the socio-demographic backgrounds of these groups, leading to an improved ability to plan for increased and efficient accessibility across different urban environments. Distinguishing between carlessness as a choice or a constraint is especially important for the most vulnerable groups in terms of sustainable mobility and access to opportunities. Understanding the dichotomy of carlessness ought to be a starting point for strategic urban development, linking land-use, transportation, life stage thinking, and housing markets increasingly together to both learn from and better serve the carless population.

\section{Appendix}

See Table 6 


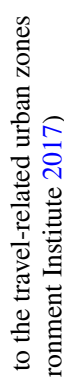

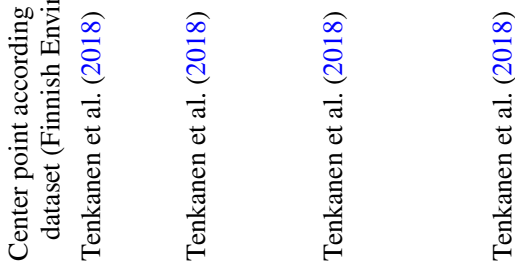

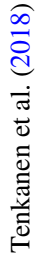

氜

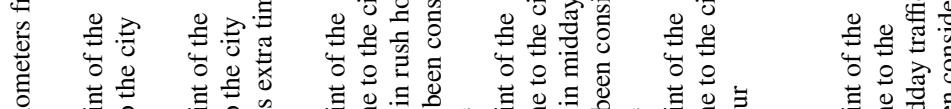

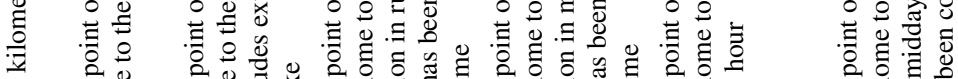

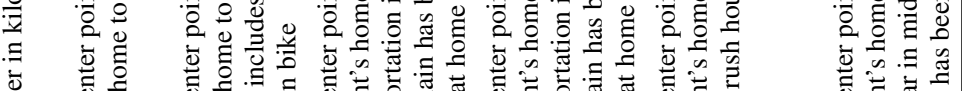

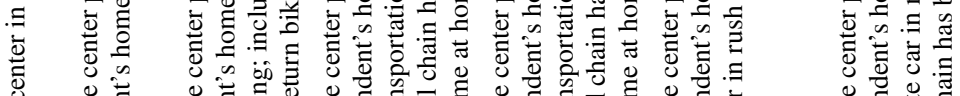

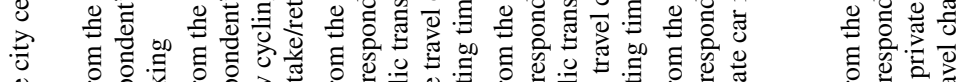

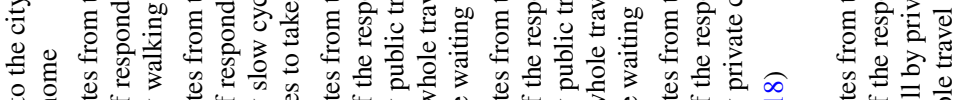

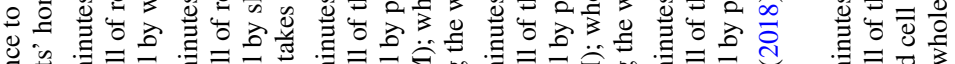

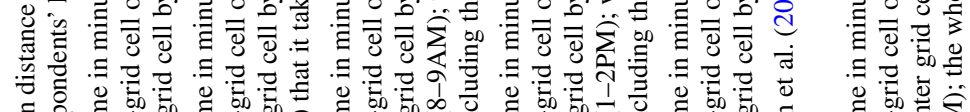

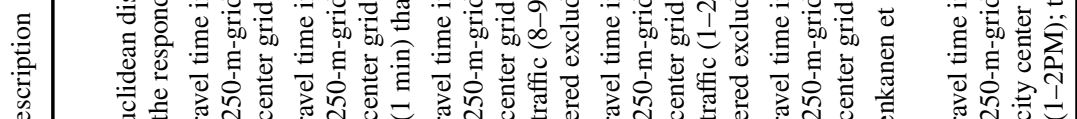

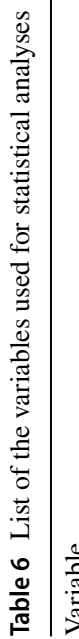
岗 矛

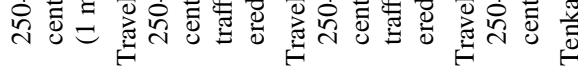
氙资言

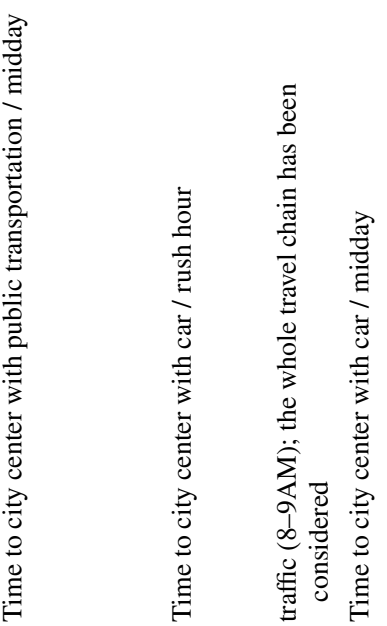




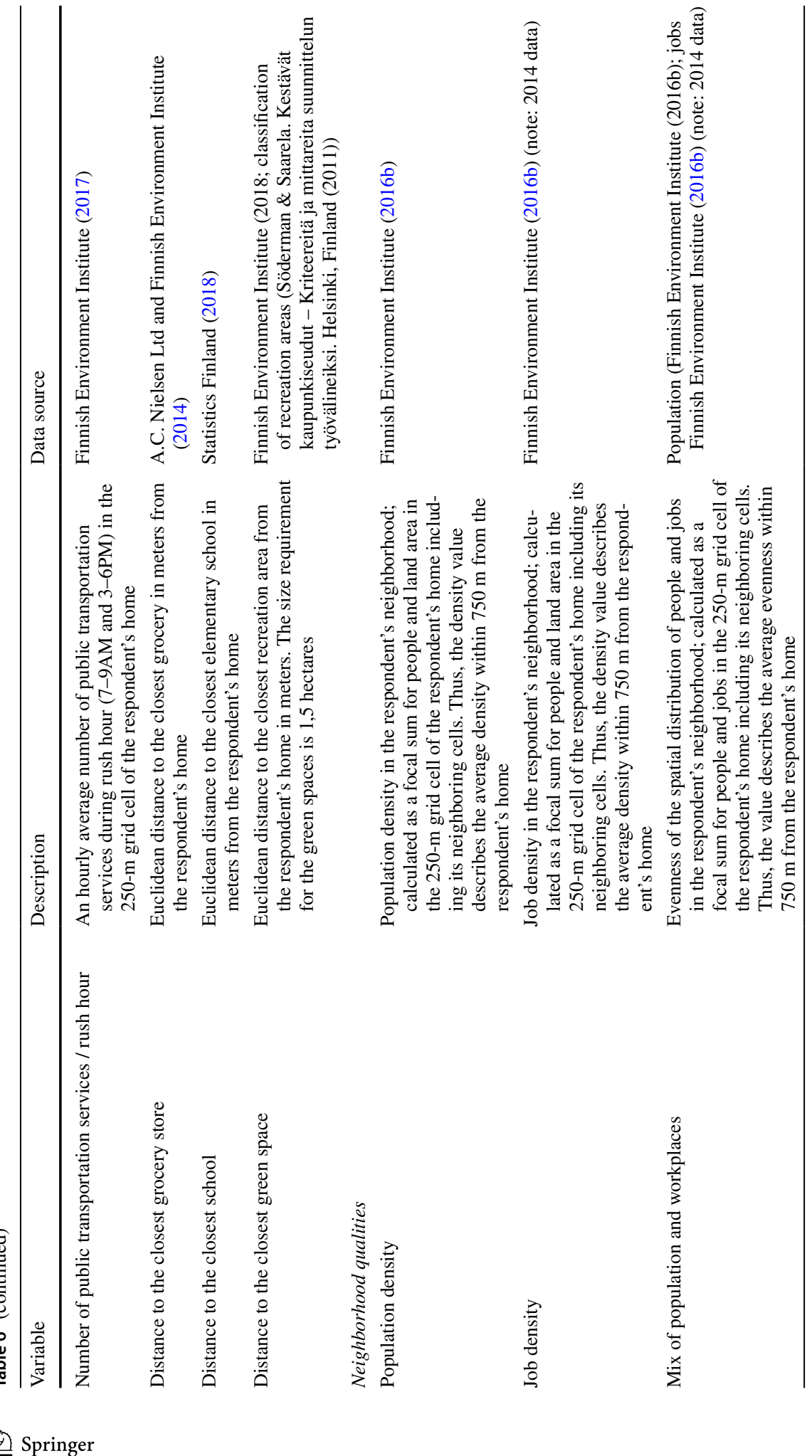




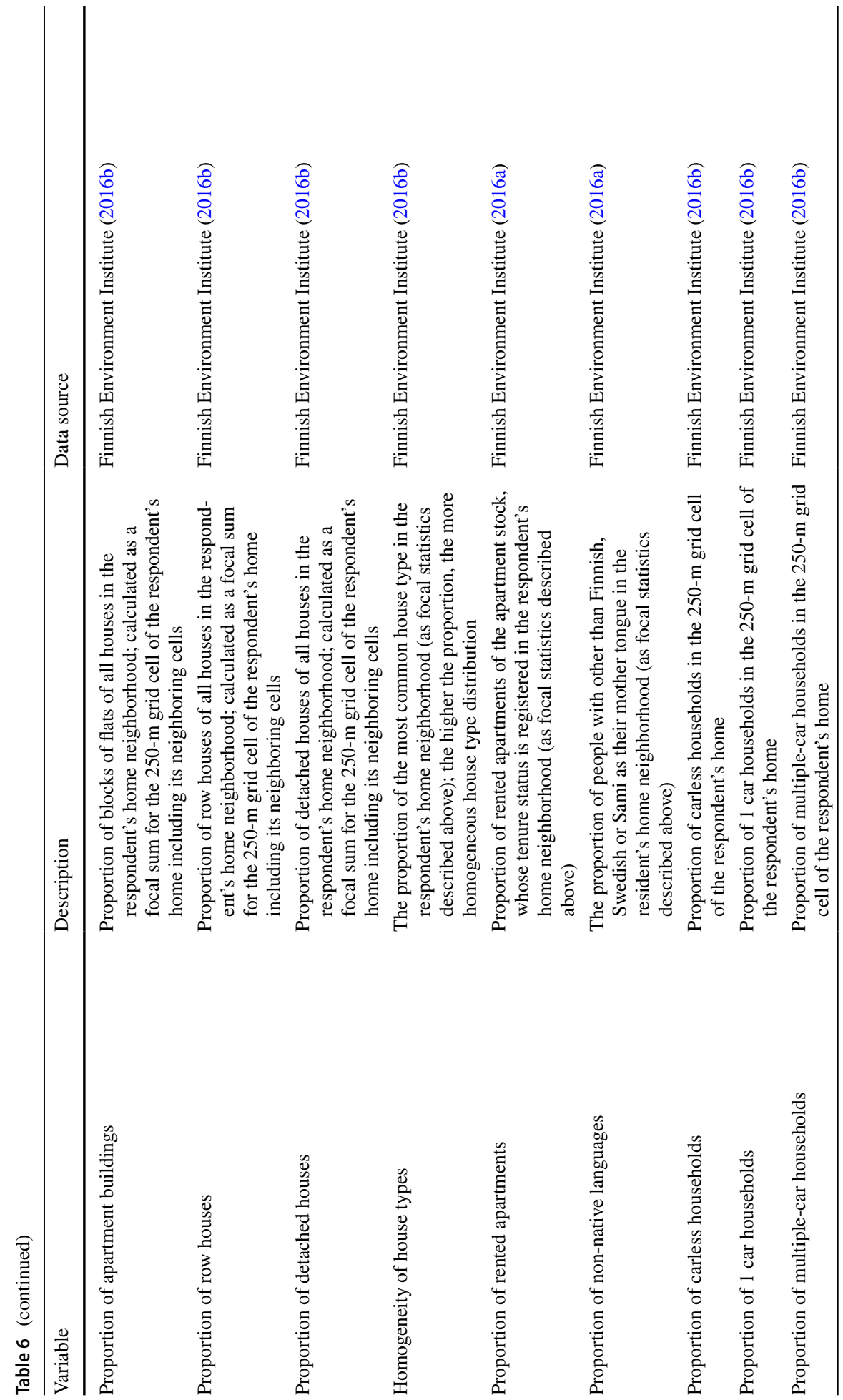




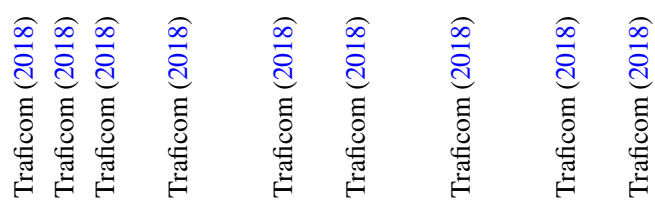

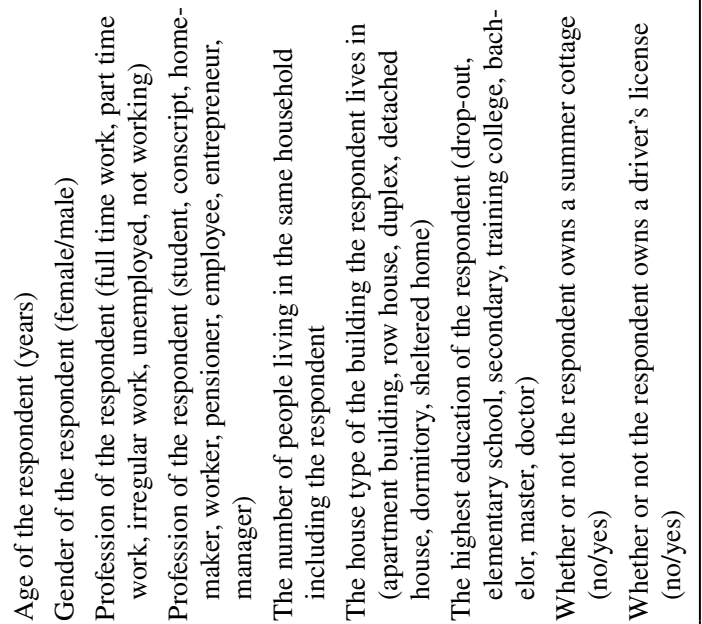

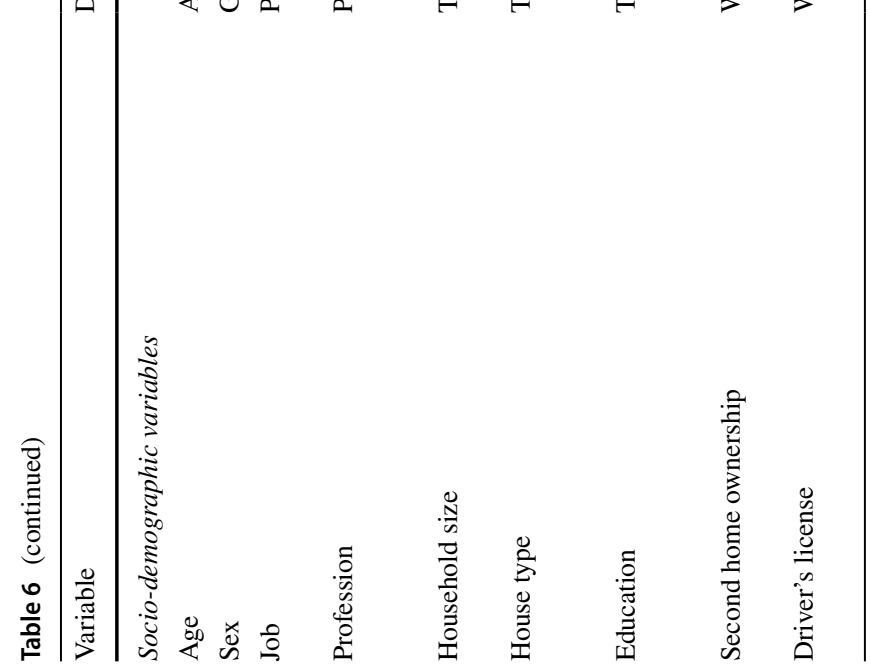


Supplementary Information The online version contains supplementary material available at https://doi. org/10.1007/s11116-021-10239-8.

Acknowledgements We thank the anonymous reviewers for their constructive comments and valuable suggestions on the previous version of this article

Author contributions Conceptualization: LK, RP, VH; Methodology: VH, MT, JL, LK, RP, TV; Formal analysis and investigation: MT, JL, RP, LK; Writing—original draft preparation: LK, RP, MT, JL, VH, JL; Writing—review and editing: AT, TV, PT.

Funding Open access funding provided by Finnish Environment Institute (SYKE). This work was supported by the Strategic Research Council (SRC) at Academy of Finland for the project Healthy Lifestyles to Boost Sustainable Growth (STYLE, project numbers 320399, 320400, 320401 and 320402).

\section{Declarations}

Conflict of interest The authors declare that they have no known competing financial interests or personal relationships that would have influenced the work reported in this paper.

Data availability See Supplementary Information for applied material. The National Travel Survey (2016) is publicly available. The Monitoring System of Spatial Structure and Urban Form database (Finnish Environment Institute 2020) is publicly available with limited data.

Open Access This article is licensed under a Creative Commons Attribution 4.0 International License, which permits use, sharing, adaptation, distribution and reproduction in any medium or format, as long as you give appropriate credit to the original author(s) and the source, provide a link to the Creative Commons licence, and indicate if changes were made. The images or other third party material in this article are included in the article's Creative Commons licence, unless indicated otherwise in a credit line to the material. If material is not included in the article's Creative Commons licence and your intended use is not permitted by statutory regulation or exceeds the permitted use, you will need to obtain permission directly from the copyright holder. To view a copy of this licence, visit http://creativecommons.org/licenses/by/4.0/.

\section{References}

A.C. Nielsen Ltd, Finnish Environment Institute. Nielsen grocery store register (2014)

Badland, H., Schofield, G.: Transport, urban design, and physical activity: an evidence-based update. Transp. Res. Part d: Transp. Environ. 10(3), 177-196 (2005). https://doi.org/10.1016/j.trd.2004.12.001

Banister, D.: Inequality in transport. Alexandrine Press, Oxford (2018)

Beimborn, E.A., Greenwald, M.J., Jin, X.: Accessibility, connectivity, and captivity: impacts on transit choice. Transp. Res. Rec. 1835(1), 1-9 (2003)

Bhat, C.R., Guo, J.Y.: A comprehensive analysis of built environment characteristics on household residential choice and auto ownership levels. Transp. Res. Part b: Methodol. 41(5), 506-526 (2007). https:// doi.org/10.1016/j.trb.2005.12.005

Blumenberg, E., Brown, A., Schouten, A.: Car-deficit households: determinants and implications for household travel in the U.S. Transportation 47(3), 1103-1125 (2018)

Brown, A.E.: Car-less or car-free? Socioeconomic and mobility differences among zero-car households. Transp. Policy 60, 152-159 (2017). https://doi.org/10.1016/j.tranpol.2017.09.016

Chevallier, L.B., Motte-Baumvol, B., Fol, S., Jouffe, Y.: Coping with the costs of car dependency: a system of expedients used by low-income households on the outskirts of Dijon and Paris. Transp. Policy 65, 79-88 (2018). https://doi.org/10.1016/j.tranpol.2017.06.006

Clark, B., Chatterjee, K., Melia, S.: Changes in level of household car ownership: the role of life events and spatial context. Transportation 43(4), 565-599 (2016). https://doi.org/10.1007/s11116-015-9589-y

Delbosc, A., Currie, G.: Choice and disadvantage in low-car ownership households. Transp. Policy 23, 8-14 (2012). https://doi.org/10.1016/j.tranpol.2012.06.006 
Ettema, D., Nieuwenhuis, R.: Residential self-selection and travel behaviour: what are the effects of attitudes, reasons for location choice and the built environment? J Transp Geogr 59, 146-155 (2017). https://doi.org/10.1016/j.jtrangeo.2017.01.009

Finnish Environment Institute. Travel-related Urban Zones (2015)

Finnish Environment Institute. Building and Dwelling Register BDR (2016a)

Finnish Environment Institute. Monitoring System of Spatial Structure and Urban Form (YKR) (2016b)

Finnish Environment Institute. Travel-related urban zones (2017)

Finnish Environment Institute. Corine Land Cover (2018)

Finnish Environment Institute. Monitoring System of Spatial Structure and Urban Form (YKR) (2020)

Focas, C., Christidis, P.: Peak Car in Europe? Transp Res. Procedia 25, 531-550 (2017)

Gössling, S., Schröder, M., Späth, P., Freytag, T.: Urban space distribution and sustainable transport. Transp. Rev. 36(5), 659-679 (2016). https://doi.org/10.1080/01441647.2016.1147101

Helminen, V., Tiitu, M., Kosonen, L., Ristimäki, M.: Identifying the areas of walking, transit and automobile urban fabrics in Finnish intermediate cities. Transp. Res. Interdiscip. Perspect. 8, 1-12 (2020)

Jacques, C., Manaugh, K., El-Geneidy, A.: Rescuing the captive [mode] user: an alternative approach to transport market segmentation. Transportation 40(3), 625-645 (2013)

Klein, N.J., Smart, M.J.: Car today, gone tomorrow: The ephemeral car in low-income, immigrant and minority families. Transportation 44, 495-510 (2017)

Kühne, K., Mitra, S.K., Saphores, J.D.M.: Without a ride in car country - A comparison of carless households in Germany and California. Transp. Res. Part a: Policy Practice 109, 24-40 (2018). https://doi. org/10.1016/j.tra.2018.01.021

Lagrell, E., Thulin, E., Vilhelmson, B.: Accessibility strategies beyond the private car: a study of voluntarily carless families with young children in Gothenburg. J. Transp. Geogr. 72, 218-227 (2018). https://doi. org/10.1016/j.jtrangeo.2018.09.002

Marttinen, R. Asuntojen hintojen ja vuokrien vuosijulkaisu 2019. In. vol. ISSN 2489-4311 (2020)

Mattioli, G.: Where Sustainable Transport and Social Exclusion Meet: Households without Cars and Car Dependence in Great Britain. J. Environ. Policy Plan. 16(3), 379-400 (2014). https://doi.org/10.1080/ 1523908x.2013.858592

Mitra, S.K., Saphores, J.D.M.: Carless in California: Green choice or misery? J. Transp. Geogr. 65, 1-12 (2017). https://doi.org/10.1016/j.jtrangeo.2017.09.016

Motte-Baumvol, B., Massot, M.H., Byrd, A.M.: Escaping car dependence in the outer suburbs of Paris. Urban Stud. 47(3), 604-619 (2010). https://doi.org/10.1177/0042098009349773

Needles Fletcher, C., Garasky, S.B., Nielsen, R.B.: Transportation hardship: are you better off with a Car? J Family Econ Issues 26(3), 323-343 (2005)

Newman, P., Kosonen, L., Kenworthy, J.: Theory of urban fabrics: planning the walking, transit/public transport and automobile/motor car cities for reduced car dependency. Town Plan. Rev. 87(4), 429-458 (2016). https://doi.org/10.3828/tpr.2016.28

Nieuwenhuijsen, M.J.: Urban and transport planning, environmental exposures and health-new concepts, methods and tools to improve health in cities. Environ. Health (2016). https://doi.org/10.1186/ s12940-016-0108-1

Nieuwenhuijsen, M.J., Khreis, H.: Car free cities: Pathway to healthy urban living. Environ. Int. 94, 251262 (2016). https://doi.org/10.1016/j.envint.2016.05.032

Noblet, C.L., Thogersen, J., Teisl, M.F.: Who attempts to drive less in New England? Transport. Res. f: Traffic Psychol. Behav. 23, 69-80 (2014). https://doi.org/10.1016/j.trf.2013.12.016

Nolan, A.: A dynamic analysis of household car ownership. Transp. Res. Part a: Policy Practice 44(6), 446455 (2010). https://doi.org/10.1016/j.tra.2010.03.018

Oakil, A.M., Ettema, D., Arentze, T., Timmermans, H.: Changing household car ownership level and life cycle events: an action in anticipation or an action on occurrence. Transportation 41(4), 889-904 (2014). https://doi.org/10.1007/s11116-013-9507-0

Saidla, K.: Health promotion by stealth: active transportation success in Helsinki Finland. Health Promot. Int. 33(4), 600-609 (2018)

Sallis, J., Cerin, E., Conway, T.L.: Physical activity in relation to urban environments in 14 cities worldwide: a cross-sectional study. Lancet 387(10034), 2207-2217 (2016)

Sattlegger, L., Rau, H.: Carlessness in a car-centric world: a reconstructive approach to qualitative mobility biographies research. J. Transp. Geogr. 53, 22-31 (2016). https://doi.org/10.1016/j.jtrangeo.2016.04. 003

Scheepers, C.E., Wendel-Vos, G.C.W., den Broeder, J.M., van Kempen, E.E.M.M., van Wesemael, P.J.V., Schuit, A.J.: Shifting from car to active transport: a systematic review of the effectiveness of interventions. Transp. Res. Part a: Policy Practice 70, 264-280 (2014). https://doi.org/10.1016/j.tra.2014.10. 015 
Scheiner, J.: Social inequalities in travel behaviour: trip distances in the context of residential self-selection and lifestyles. J. Transp. Geogr. 18(6), 679-690 (2010). https://doi.org/10.1016/j.jtrangeo.2009.09.002

Sheller, M., Urry, J.: The city and the car. Int. J. Urban Reg. Res. 24(4), 737-757 (2000). https://doi.org/10. 1111/1468-2427.00276

Statistics Finland. Statistics (2018)

Steenberghen, T., Tavares, T., Richardson, J., Himpe, W., Crabbé, A. Support study on data collection and analysis of active modes use and infrastructure in Europe - Final report. European Commission, Luxembourg, (2017)

Steg, L.: Car use: lust and must. Instrumental symbolic and affective motives for car use. Transp. Res. Part A: Policy Practice 39(2-3), 147-162 (2005). https://doi.org/10.1016/j.tra.2004.07.001

Tenkanen, H., Espinosa, J.L., Willberg, E., Heikinheimo, V., Tarnanen, A., Jaakkola, T., Järvi, J., Salonen, M., Toivonen, T. Helsinki Region Travel Time Matrix dataset (2018). Doi: https://doi.org/10.13140/ RG.2.2.20858.39362

Terämä, E., Tiitu, M., Paavola, J.-P., Vainio, A., Määttänen, N., Miettinen, A., Kontula, A., Hiilamo, H. Living alone as part of the life course. In: Publications of the Government's analysis, assessment and research activities 66/2018 (2018)

Traficom. National Travel Survey 2016 (2018)

Tuominen, A., Rehunen, A., Peltomaa, J., Mäkinen, K.: Facilitating practices for sustainable car sharing policies-An integrated approach utilizing user data, urban form variables and mobility patterns. Trans. Res. Interdiscip. Perspect. 2, 1-11 (2019)

Van Acker, V., Witlox, F.: Car ownership as a mediating variable in car travel behaviour research using a structural equation modelling approach to identify its dual relationship. J. Transp. Geogr. 18(1), 65-74 (2010). https://doi.org/10.1016/j.jtrangeo.2009.05.006

Vandecasteele, I., Baranzelli C., Siragusa A., Aurambout J.P., Alberti V., Alonso Raposo M., Attardo C., Auteri D., Barranco R., Batista e Silva F., Benczur P., Bertoldi P., Bono F., Bussolari I., Caldeira S., Carlsson J., Christidis P., Christodoulou A., Ciuffo B., Corrado S., Fioretti C., Galassi M. C., Galbusera L., Gawlik B., Giusti F., Gomez J., Grosso M., Guimarães Pereira Â., Jacobs-Crisioni C., Kavalov B., Kompil M., Kucas A., Kona A., Lavalle C., Leip A., Lyons L., Manca A.R., Melchiorri M., Monforti-Ferrario F., Montalto V., 'Mortara B., Natale F., Panella F., Pasi G., Perpiña C., Pertoldi M., Pisoni E., Polvora A., Rainoldi A., Rembges D., Rissola G., Sala S., Schade S., Serra N., Spirito L., Tsakalidis A., Schiavina M., Tintori G., Vaccari L., Vandyck T., Vanham D., Van Heerden S., Van Noordt C., Vespe M., Vetters N., Vilahur Chiaraviglio N., Vizcaino P., Von Estorff U., Zulian G. The Future of Cities - Opportunities, challenges and the way forward. Publications Office, Luxembourg, (2019)

von Behren, S., Bonisch, L., Niklas, U., Chlond, B.: Revealing motives for car use in modern cities-a case study from Berlin and San Francisco. Sustainability (2020). https://doi.org/10.3390/su12135254

Vuori, P., Kaasila, M. Helsingin ja Helsingin seudun väestöennuste 2019-2060: Ennuste alueittain 20192035. ISSN 2489-4311 (2020)

World Health Organization. Physical activity factsheets for the 28 European Union Member States of the WHO European Region (2018). Available online https://www.euro.who.int/_data/assets/pdf_file/ 0005/382334/28fsphysical-activity-euro-rep-eng.pdf

Publisher's Note Springer Nature remains neutral with regard to jurisdictional claims in published maps and institutional affiliations.

L. E. Karjalainen is a researcher at the Environmental Policy Centre, Finnish Environment Institute (SYKE). She is also a doctoral candidate and a member of the Urban Environmental Policy research group at the University of Helsinki. Currently, her research focuses on the conceptualization and operationalization of 'sustainability' in urban transportation planning and policy-making with special attention paid to social equity and the role of citizens. Her research interests also include active mobility, physical activity in urban areas, social justice, and sustainable urban planning on a broader scale.

M. Tiitu is specialized in spatial analysis of urban form. She holds a master's degree in geography from the University of Helsinki and is currently working as a researcher at the Environmental Policy Centre, Finnish Environment Institute. She focuses on studying interlinkages between different functions of city regions, such as land use, mobility, and green infrastructure. Her research topics also cover developing GIS-based tools and knowledge co-production processes with city practitioners in various research projects to support sustainable urban planning. 
Dr. J. Lyytimäki is a leading researcher at the Environmental Policy Centre, Finnish Environment Institute (SYKE) and an adjunct professor at the University of Helsinki. He has over 20 years of experience from various EU-funded and national R\&D projects focusing on sustainable development, environmental reporting, climate communication, risk assessment and management and various aspects of environmental policy. He has authored or co-authored about 100 refereed articles and chapters in scholarly journals and books as well as numerous books and reports. He is also an enthusiastic science communicator with over 500 popular contributions, ranging from policy briefs to newspaper and online articles. Emerging environmental issues and transdisciplinary research approaches are close to his heart.

V. Helminen is a Head of unit at the Environmental Policy Centre, Finnish Environment Institute (SYKE). He holds an M.S. degree in planning geography from the University of Helsinki. Helminen has been working in SYKE as a researcher since 2002. His research interests include GIS-based studies of urban form, urban and regional trends, and geographies of transport and mobility.

P. Tapio is Professor of Futures Research at Finland Futures Research Centre, University of Turku and the responsible teacher of the major subject of Futures Studies containing both Master's and Doctoral studies. His research interest is in interdisciplinary scrutiny of the sustainable future of transport and energy sectors, as well as futures research methodology. He has led and is leading multiple consortium projects on these topics funded by the Strategic Research Council and Academy of Finland. Professor Tapio has published more than hundred academic papers.

A. Tuominen (D.Sc.Tech.) is a principal scientist at the VTT Technical Research Centre of Finland Ltd. Prior to the present position she has worked for VTT as a research team leader and senior scientist since 1997 and as a transport consultant at Pöyry PLC. Her professional experience lies in the fields of transport policy analysis, system-level impact assessment, technology foresight and socio-technical change in which areas, she has coordinated and participated in several national and international research projects.

T. Vasankari, Professor, MD, PhD, is a director at the UKK Institute for Health Promotion Research and a part-time professor at Faculty of Medicine and Health Technology, Tampere university. Earlier he has served professor of health and exercise at Medical School of Turku University. Prof. Vasankari has and have had many national and international positions of trust in the fields of physical activity and health. He was a chairman of the Steering Committee of the WHO HEPA Europe network at 2013-2017. Currently he is a President of the Finnish Diabetes Association. He has also taken part to several national physical activity actions lead by the Finnish Government and NGOs. His research expertise focuses on accelerometer-based measurement of physical activity, sedentary behavior and sleep in both population samples and interventions aiming to increase physical activity and reduce sedentary behavior. He has published more than 250 international peer-review scientific articles.

Dr. J. Lehtimäki is a senior researcher at the Environmental Policy Centre, Finnish Environment Institute (SYKE). Her research interests include the associations between biodiverse, green environments and noncommunicable diseases, such as asthma. As current evidence suggests that exposure to microbial organisms can be the link between biodiversity and human health, Lehtimäki studies these associations in more detail, and brings this knowledge to practical solutions.

Dr. R. Paloniemi works as a head of behavioral change unit at the Environmental Policy Centre, Finnish Environment Institute (SYKE). Her interdisciplinary research covers various aspects of sustainability and aims to create prerequisites for more sustainable behavior, policy and decision making. Recently, she has been leading numerous practice and policy relevant research and development projects exploring, for example, knowledge use in spatial planning, social learning in biodiversity conservation and prerequisites for sustainable, healthy mobility. Moreover, she participates actively in science-policy-society dialogue supporting sustainability transition. 